\title{
O QUE OS ISÓTOPOS DE ESTRÔNCIO NOS ENSINAM SOBRE AS ÁGUAS SUBTERRÂNEAS
}

\author{
Carolina Stager QUAGGIO
}

Didier GASTMANS

Veridiana Teixeira de Souza MARTINS

\begin{abstract}
RESUMO
As razões entre os isótopos de estrôncio $\left({ }^{87} \mathrm{Sr} /{ }^{86} \mathrm{Sr}\right)$ constituem excelentes traçadores de processos hidrogeoquímicos. Isso se deve a sua característica conservativa, ou seja, não serão fracionados por processos geológicos superficiais, como, por exemplo, processos de interação água-rocha, de intemperismo, de salinização e na determinação de fontes de ${ }^{87} \mathrm{Sr}$, constituindo informação relevante na compreensão da circulação das águas subterrâneas. No Brasil, poucos estudos hidrogeológicos utilizaram essas razões entre os isótopos de estrôncio na compreensão de processos hidrogeoquímicos. A pouca utilização desta técnica versátil está associada ao pequeno número de laboratórios brasileiros com capacidade analítica para a determinação das razões ${ }^{87} \mathrm{Sr} /{ }^{86} \mathrm{Sr}$ em águas subterrâneas, uma vez que são necessários equipamentos de elevada precisão, como espectrômetros de massa por termo-ionização (TIMS) ou plasma indutivamente acoplado (ICP-MS), equipe e infraestrutura especializada. Além disso, devido à complexidade da interpretação dos resultados, são necessários dados complementares e um profundo conhecimento do contexto hidrogeológico. Neste sentido, o presente trabalho busca incentivar o uso dos isótopos de estrôncio e, para tanto, traz a apresentação dos conceitos principais para compreensão e avaliação dos isótopos de estrôncio em águas subterrâneas, iniciando com a revisão dos fundamentos teóricos acerca da geoquímica do estrôncio, seus isótopos e o ciclo desses isótopos. Na sequência, são apresentados os procedimentos de amostragem e análise, seguidos pela revisão dos estudos de águas subterrâneas brasileiros que utilizaram este traçador. Por fim, considerações sobre a técnica e oportunidades de aplicação em estudos hidrogeológicos são apresentadas. Visto que a grande maioria dos sistemas aquíferos brasileiros não possuem dados da razão ${ }^{87} \mathrm{Sr} /{ }^{86} \mathrm{Sr}$, há grandes oportunidades de expansão desta linha de pesquisa, com produção de dados inéditos e inclusão deste traçador em programas de monitoramento de águas subterrâneas.
\end{abstract}

Palavras-chaves: Isótopos de estrôncio; Águas subterrâneas; Aquíferos; Brasil.

\begin{abstract}
WHAT STRONTIUM ISOTOPES TEACH US ABOUT GROUNDWATER. The ratio between the strontium isotopes $\left({ }^{87} \mathrm{Sr} r{ }^{86} \mathrm{Sr}\right)$ is an excellent hydrogeochemical tracer. Thanks to its conservative characteristic, which means that no fractionation will take place in face of geological superficial processes, for example, water-rock interaction, weathering, salinization processes and in the determination of ${ }^{87} \mathrm{Sr}$ sources, strontium isotopes constitute relevant information to understand groundwater circulation. In Brazil, there are few hydrogeological studies that use strontium isotopes to assess hydrogeochemical processes. The little use of this versatile technique is explained by the restricted number of laboratories in Brazil with analytical capacity to determine ${ }^{87} \mathrm{Sr}{ }^{86} \mathrm{Sr}$ ratios in groundwater, since high-resolution equipment - such as thermal ionization (TIMS) and inductively coupled plasma (ICP-MS) mass spectrometers -, specialized teams and infrastructure are required. Furthermore, there is the complexity of the interpretation of the results, which requires complementary data and deep
\end{abstract}


knowledge of the hydrogeological context. In this sense, this paper aims to motivate the use of strontium isotopes by presenting the key concepts to comprehend and determine strontium isotopes in groundwater, starting with the review of the theoretical concepts of the strontium geochemistry, strontium isotopy and the strontium isotope cycle. Sampling and analytical procedures are presented, followed by a review of groundwater studies that have applied this tracer in Brazil. Final considerations and the presentation of opportunities to apply the strontium isotope technique to hydrogeological studies are made. Since ${ }^{87} \mathrm{Sr} /{ }^{86} \mathrm{Sr}$ data are lacking for the majority of the Brazilian aquifer systems, the opportunity exists to expand this line of research to produce unprecedented data and to include strontium isotopes in groundwater monitoring programs.

Keywords: Strontium isotopes; Groundwater; Aquifers; Brazil.

Lista de siglas:

Sistema Aquífero (S.A.)

S.A. Beberibe (SABB)

S.A. Boa Vista (SABV)

S.A. Cabo (SACB)

S.A. Pirabas (SAP)

S.A. Sedimentar (SAS)

S.A. Tubarão (SAT)

\author{
S.A. Bauru (SAB) \\ S.A. Barreiras (SABR) \\ S.A. Cristalino (SAC) \\ S.A. Guarani (SAG) \\ S.A. Pré-Cambriano (SAPC) \\ S.A. Serra Geral (SASG)
}

\section{INTRODUÇÃO}

O uso de razões isotópicas como traçadoras da movimentação da água subterrânea e de suas interações com o arcabouço geológico dos aquíferos vem se difundindo cada vez mais. Esses traçadores, além de capazes de fornecer informações sobre a idade e origem das águas subterrâneas, possibilitam ainda a avaliação de sua qualidade e da sua evolução geoquímica, dos processos de recarga, das interações água-rocha, da origem da sua salinização e de fontes de contaminação (CLARK \& FRITZ 1997, JASECHKO 2019).

As variações existentes nas razões entre os isótopos de estrôncio (razão ${ }^{87} \mathrm{Sr} /{ }^{86} \mathrm{Sr}$ ) constituem excelentes indicadores de processos geoquímicos e são utilizados com frequência em estudos hidrogeológicos (BRENOT et al. 2008, PETELETGIRAUD et al. 2016, SANTONI et al. 2021), forenses (AGGARWAL et al. 2008, WEST et al. 2009, WEBB-ROBERTSON et al. 2012), arqueológicos (LAFFOON et al. 2012, WILHELMSON \& AHSLTROM 2015, KLOPPMANN et al. 2017) e de migração de espécies a partir de hábitos alimentares (CHENERY et al. 2010, BRENNAN et al. 2014, VAUTOUR et al. 2015).

As variações naturais da razão isotópica ${ }^{87} \mathrm{Sr} /{ }^{86} \mathrm{Sr}$ são governadas pelo decaimento natural do rubídio $\left({ }^{87} \mathrm{Rb}\right)$, que dá origem ao ${ }^{87} \mathrm{Sr}$ radiogê- nico. O interesse na aplicação geoquímica dos isótopos de estrôncio, em grande parte, é devido a seu caráter conservativo, uma vez que a razão entre seus isótopos não se modifica por processos geoquímicos superficiais, ou seja, não há fracionamento entre seus isótopos nessas reações químicas (SHAND et al. 2009), mantendo a razão isotópica de estrôncio ao longo dos processos geoquími$\cos$, e fornecem a assinatura isotópica natural do meio (MCNUTT 2000), como impressões digitais naturais da interação rocha-água (BLUM \& EREL 2003), potencializando seu uso como traçador.

A aplicação dos isótopos de estrôncio em estudos hidrogeoquímicos, especialmente em águas subterrâneas, fornece informações que possibilitam delimitar os caminhos percorridos pelas águas subterrâneas, auxiliando na determinação de sua origem e na compreensão de anomalias hidrogeoquímicas, especialmente em complexos contextos hidrogeológicos (CARY et al. 2015, BAUBLYS et al. 2019, LUÍS et al. 2019). Por meio de distintas razões ${ }^{87} \mathrm{Sr} /{ }^{86} \mathrm{Sr}$ presentes em águas subterrâneas, é possível obter informações adicionais, como o tipo de rocha e o processo de intemperismo dominante, quando analisada a abundância de outros elementos e a assinatura isotópica de estrôncio das rochas armazenadoras (FAURE 1986, MCNUTT 2000, BLUM \& EREL 2003). 
A razão isotópica ${ }^{87} \mathrm{Sr} /{ }^{86} \mathrm{Sr}$ em águas subterrâneas é capaz de complementar informações obtidas por meio da avaliação de características físicas e químicas da água (BAKARI et al. 2013), constituindo um importante traçador para a definição de mistura entre águas subterrâneas e identificação de aspectos relacionados à interação água-rocha (BLUM \& EREL 2003, FROST \& TONER 2004, SHAND et al. 2009), assim como no diagnóstico e monitoramento de áreas contaminadas por atividades antrópicas (XIE et al. 2013, NIGRO et al. 2017).

O uso desta técnica versátil ainda é incipiente em estudos hidrogeológicos no Brasil, apesar do uso rotineiro dos isótopos de estrôncio em estudos quimioestratigráficos (TAMAYO 2004, CAMPOS 2011, CUNHA 2015). A sua aplicação na hidrogeologia constitui uma linha de pesquisa consolidada internacionalmente, porém emergente no Brasil, o que torna seu uso uma inovação em estudos hidrogeológicos brasileiros. Nesse sentido, o presente artigo busca introduzir os conceitos essenciais para a compreensão e aplicação dos isótopos de estrôncio. Além da introdução i), este artigo conta com: ii) revisão dos conceitos principais dos isótopos de estrôncio, associados a seu comportamento geoquímico; iii) ciclo geoquímico do estrôncio e seus isótopos, focando na sua mobilidade entre os compartimentos da Terra (geosfera, atmosfera, biosfera e hidrosfera); iv) descrição dos procedimentos de amostragem e análise isotópica do estrôncio; v) revisão de pesquisas brasileiras que fizeram uso dos isótopos de estrôncio em águas subterrâneas; e vi) considerações acerca do cenário atual e das oportunidades desta linha de pesquisa no Brasil.

\section{FUNDAMENTAÇÃO TEÓRICA: ISÓTOPOS DE ESTRÔNCIO}

Um mesmo elemento químico pode possuir diferentes números de massa e assim ter diferentes isótopos. A massa do elemento é determinada pelo número de prótons $(\mathrm{Z}=$ número atômico) somados ao número de nêutrons $(\mathrm{N})$. $\mathrm{O} Z$ define qual é o elemento químico e o $\mathrm{N}$ vai determinar qual o isótopo. Os isótopos dos elementos químicos são divididos em dois grupos principais, os estáveis e os radioativos/radiogênicos. A proporção entre o número de nêutrons $(\mathrm{N})$ e o número de prótons $(\mathrm{Z})$ no núcleo do átomo é que define se o núcleo é estável ou instável. Até o número atômico $20(Z=20)$, a grande estabilidade dos núcleos ocorre quando a proporção entre $\mathrm{Z}$ (número atômico) e $\mathrm{N}$ (núme- ro de nêutrons) é de aproximadamente um ( $\mathrm{Z}: \mathrm{N}=$ 1:1), mas a partir de $Z=20$, em direção a $Z$ maiores, essa relação aumenta até 1: 1,5 (CLARK \& FRITZ 1997). Ou seja, maiores números atômicos necessitam de maiores números de nêutrons, para evitar que os prótons eletricamente carregados se afastem e quebrem o núcleo (ALLĖGRE 2008). Portanto, se $\mathrm{N}$ for muito maior do que o número atômico, teremos núcleos instáveis, ou seja, que emitem radiação para satisfazer a Lei de Conservação de Energia e Massa e equilibrar as forças. A radioatividade não depende da temperatura, pressão ou ligações químicas e o decaimento radioativo tem a mesma probabilidade de ocorrer por uma unidade de tempo, em qualquer ambiente do Sistema Solar, não há variações mensuráveis ao longo do tempo geológico (ALBAREDE 2011). Essa probabilidade é constante no tempo e é chamada de constante de decaimento.

São chamados de isótopos ambientais, aqueles que ocorrem naturalmente, em abundância no nosso planeta e fazem parte dos ciclos hidrológico, geológico e biológico, como o $\mathrm{H}, \mathrm{C}, \mathrm{N}, \mathrm{O}$ e S (CLARK \& FRITZ 1997). Podem ser estáveis $\left({ }^{1} \mathrm{H},{ }^{2} \mathrm{H},{ }^{12} \mathrm{C},{ }^{13} \mathrm{C}\right)$ ou radioativos/radiogênicos $\left({ }^{14} \mathrm{C}\right.$, $\left.{ }^{3} \mathrm{H}\right)$. Também são os pioneiros das análises isotópicas, por serem mais abundantes, possuírem menores massas (são mais leves) e serem mais fáceis de quantificar. Os isótopos estáveis mais pesados, não abundantes, que ocorrem como traços nos materiais terrestres, foram possíveis de serem analisados mais recentemente (a partir dos anos 2000) e são chamados de isótopos não-tradicionais, incluindo-se aqui os isótopos de elementos como $\mathrm{Fe}$, $\mathrm{Cu}, \mathrm{Zn}, \mathrm{Cr}$, dentre outros. Há ainda os isótopos radiogênicos (filhos), de massas mais pesadas, com pouca abundância em relação aos isótopos ambientais, e os estáveis não tradicionais, que são fruto de decaimento radioativo de elementos de núcleos instáveis (pais, radioativos), como o estrôncio, com massa atômica $87\left({ }^{87} \mathrm{Sr}\right)$, derivado do decaimento do rubídio $\left({ }^{87} \mathrm{Rb}\right)$, ou o chumbo com massa atômica $206\left({ }^{206} \mathrm{~Pb}\right)$, que é derivado do decaimento radioativo do urânio $\left({ }^{238} \mathrm{U}\right)$.

$\mathrm{O}$ estrôncio $(\mathrm{Sr})$ é um elemento alcalino terroso pertencente ao Grupo IIA da tabela periódica, de número atômico 38 e massa atômica de 87,62 ponderada pela abundância de seus isótopos. O estrôncio é um elemento facilmente encontrado em quantidades mensuráveis em uma grande variedade de rochas, apesar de classificado geoquimicamente como um elemento traço (MCNUTT 2000). Esse elemento possui quatros isótopos naturais 
${ }^{88} \mathrm{Sr},{ }^{87} \mathrm{Sr},{ }^{86} \mathrm{Sr}$ e ${ }^{84} \mathrm{Sr}$, com abundância variável de $82,53 \%, 7,04 \%, 9,87 \%$ e $0,56 \%$, respectivamente. Todos os isótopos de estrôncio são estáveis e ${ }^{87} \mathrm{Sr}$ constitui o único isótopo que é gerado pelo decaimento radioativo de seu elemento pai, o Rubídio $(\mathrm{Rb})$, ao longo do tempo geológico, enquanto os demais foram gerados durante a nucleossíntese. $\mathrm{O}$ decaimento do ${ }^{87} \mathrm{Rb}$ para ${ }^{87} \mathrm{Sr}$ ocorre com a liberação de energia e de duas partículas nucleares, uma partícula beta e uma partícula anti-neutrino, representado pela equação 1 (FAURE 1986, CAPO et al. 1998, BANNER 2004).

$$
{ }^{87} \mathrm{Rb} \rightarrow{ }^{87} \mathrm{Sr}+\beta^{-}
$$

Os valores da razão isotópica ${ }^{87} \mathrm{Sr} /{ }^{86} \mathrm{Sr}$ são muito baixos, observando-se a variação entre a segunda e quinta casas decimais. Esta característica é devida a baixa abundância do estrôncio e a pequena diferença relativa das massas dos isótopos ${ }^{87} \mathrm{Sr} \mathrm{e}$ ${ }^{86} \mathrm{Sr}$, de apenas $1,15 \%$ (BANNER 2004).

$\mathrm{O}{ }^{87} \mathrm{Sr}$ é o único isótopo de estrôncio cuja concentração varia com o tempo, uma vez que sua produção é constante a partir do decaimento do ${ }^{87} \mathrm{Rb}$, de maneira que ao longo do tempo as razões isotópicas ${ }^{87} \mathrm{Sr} /{ }^{86} \mathrm{Sr}$ observadas nas rochas/minerais tendem a aumentar. A meia vida de seu elemento-pai, $\mathrm{o}^{87} \mathrm{Rb}\left(\mathrm{T}_{1 / 2}=4,88 \times 10^{9}\right.$ anos $)$, é suficiente para que existam variações detectáveis na razão isotópica ${ }^{87} \mathrm{Sr} /{ }^{86} \mathrm{Sr}$ encontrada atualmente nos minerais formadores de rochas. Devido a afinidade geoquímica do rubídio $(\mathrm{Rb})$ com o potássio $(\mathrm{K})$ e do estrôncio $(\mathrm{Sr})$ com o cálcio $(\mathrm{Ca})$, minerais com alta relação $\mathrm{K} / \mathrm{Ca}$ tendem a desenvolver maiores razões isotópicas ${ }^{87} \mathrm{Sr} /{ }^{86} \mathrm{Sr}$ (MCNUTT 2000, BANNER 2004) do que minerais de mesma idade com baixas razões $\mathrm{K} / \mathrm{Ca}$. Os minerais que contem $\mathrm{Rb}$ em abundância são os minerais portadores de K: muscovita, biotita, ortoclásio, microclínio, argilas (ilita) e evaporitos (silvita e carnalita). Os principais minerais portadores de estrôncio são aqueles onde o Sr substitui o Ca são: plagioclásio, apatita, sulfatos (gipso e anidrita) e carbonatos (calcita, dolomita e aragonita) (CAPO et al. 1998). O decaimento $\mathrm{de}^{87} \mathrm{Rb}$, e consequente aumento da razão isotópica ${ }^{87} \mathrm{Sr} r{ }^{86} \mathrm{Sr}$, está relacionado à idade da rocha e pode ser expresso matematicamente pela equação abaixo (MCNUTT 2000, BANNER 2004):

$\left({ }^{87} \mathrm{Sr} /{ }^{86} \mathrm{Sr}\right)_{\mathrm{t}}=\left({ }^{87} \mathrm{Sr} /{ }^{86} \mathrm{Sr}\right)_{0}+\left({ }^{87} \mathrm{Rb} /{ }^{86} \mathrm{Sr}\right)_{\mathrm{t}} \mathrm{x}\left(\mathrm{e}^{\lambda \mathrm{t}}-1\right)$ Eq. 2

Onde: 0 e t representam, respectivamente, o tempo inicial de formação da rocha e o tempo atual e $\lambda$ é a taxa de decaimento radioativo do ele- mento pai, no caso do ${ }^{87} \mathrm{Rb}, \lambda=1,42 \times 10^{-11}$ anos ${ }^{1}$. Ou seja, a razão isotópica ${ }^{87} \mathrm{Sr} /{ }^{86} \mathrm{Sr}$ atual é definida pela razão isotópica ${ }^{87} \mathrm{Sr} r{ }^{86} \mathrm{Sr}$ inicial somada à razão isotópica ${ }^{87} \mathrm{Sr} /{ }^{86} \mathrm{Sr}$ produzida pelo decaimento do ${ }^{87} \mathrm{Rb}$, ao longo do tempo de existência da rocha ou mineral.

A característica da produção de estrôncio pelo decaimento do elemento-pai, o rubídio, o define como um isótopo radiogênico e estável. Os isótopos radiogênicos constituem excelentes traçadores da circulação, recarga e idade das águas subterrâneas (COOK 2020), notavelmente distintos dos isótopos estáveis mais utilizados na hidrogeoquímica, os isótopos de oxigênio e hidrogênio, que constituem excelentes traçadores das transformações físicas da água (JASECHKO 2019), utilizados frequentemente para associação da recarga das águas subterrâneas a controle climáticos da atmosfera (COPLEN et al. 2000).

Os isótopos de estrôncio não são fracionados por processos geológicos superficiais, ao contrário de isótopos de elementos mais leves, e nem por processos biológicos envolvidos no metabolismo das plantas e animais (CAPO et al. 1998), o que confere a esses isótopos seu caráter conservativo (BANNER 2004). Ou seja, os dois isótopos (87 e 86), preferem os mesmos lados das reações químicas da superfície e caminham junto, não havendo acúmulo preferencial de uma massa em relação à outra em determinadas condições do ambiente (líquido, sólido, gasoso, redutor ou oxidante). $\mathrm{O}$ intemperismo químico libera estrôncio das rochas na forma dissolvida para as águas armazenadas nos oceanos, lagos, rios e aquíferos, cada qual com uma razão isotópica ${ }^{87} \mathrm{Sr} /{ }^{86} \mathrm{Sr}$ própria (MCNUTT 2000), relacionada às razões das rochas que estão em contato com as águas desses ambientes (Tabela 1).

A razão ${ }^{87} \mathrm{Sr} r{ }^{86} \mathrm{Sr}$ da água do mar, considerada o início do ciclo hidrológico, constitui valor de referência para a maior parte das aplicações. É importante em estudos estratigráficos em que os isótopos de estrôncio são utilizados como marcadores geoquímicos do ambiente em que essas rochas foram depositadas, pois apresenta variações da razão ao longo do tempo geológico em função de mudanças no aporte sedimentar dos continentes, das condições diagenéticas do arcabouço geológico marinho e do fluxo hidrotermal relacionado à tectônica dos oceanos (BANNER 2004). Assume-se o valor de 0,7092 como padrão para a razão isotópica ${ }^{87} \mathrm{Sr} /{ }^{86} \mathrm{Sr}$ da água do mar moderna, uma vez que o estrôncio presente no mar possui distribuição homogênea entre os oceanos do mundo (VEIZER 1989); e repre- 
TABELA 1 -Alguns valores de referência para assinaturas isotópicas de estrôncio em rochas e águas.

\begin{tabular}{|c|c|c|c|c|}
\hline AMOSTRA & MATRIZ & LOCAL & ${ }^{87} \mathrm{Sr} /{ }^{86} \mathrm{Sr}$ & AUTOR \\
\hline Rio Negro & & & $0,71622-0,72784$ & \multirow{3}{*}{$\begin{array}{l}\text { GALARDET et al. } \\
\text { (1997) }\end{array}$} \\
\hline Rio Solimões & Águas superficiais & Amazonas (AM) & 0,70877 & \\
\hline Rio Amazonas & & & $0,70917-0,71147$ & \\
\hline $\begin{array}{l}\text { Basaltos - Form. Serra } \\
\text { Geral }\end{array}$ & Rochas & $\begin{array}{l}\text { Toda extensão da Bacia } \\
\text { do Paraná }\end{array}$ & $0,70548-0,70654$ & $\begin{array}{l}\text { METAL MINING } \\
\text { JAPAN AGENCY } \\
(2003)\end{array}$ \\
\hline Rio Ganges & Águas superficiais & Índia & 0,7257 & BANNER (2004) \\
\hline Crosta continental & Rochas & & 0,716 & \multirow{2}{*}{ CAPO et al. (1998) } \\
\hline Mar moderno & Águas do mar & & 0,7092 & \\
\hline
\end{tabular}

senta a mistura de assinaturas não radiogênicas da crosta oceânica $(\sim 0,7035)$ com razões mais radiogênicas $(\sim 0,712)$ da crosta continental (EDMOND 1992, HALVERSON et al. 2007). A partir da análise de sedimentos marinhos autigênicos, especificamente de fósseis e rochas carbonáticas e evaporíticas, BURKE et al. (1982) construíram uma curva de variação secular da razão isotópica ${ }^{87} \mathrm{Sr} /{ }^{86} \mathrm{Sr}$ da água do mar, para o eon Fanerozoico, conhecida como a curva de Burke ("Burke's curve"). A criação da curva de Burke foi um marco nos estudos envolvendo isótopos de estrôncio, pois possibilitou relacionar essas variações de estrôncio no mar, ao longo do tempo, com variações climáticas, químicas, tectônicas e melhorar correlações estratigráficas (BANNER 2004). Posteriormente, HALVERSON et al. (2007) apresentam uma nova curva (Figura 1), de alta resolução, para as águas do mar durante o
Neoproterozoico (1000-542 Ma), com a adição de novos dados isotópicos de estrôncio, associados a dados de $\delta^{13} \mathrm{C}$ de rochas carbonáticas.

\section{CICLO GEOQUÍMICO DO ESTRÔNCIO}

O ciclo geoquímico do estrôncio representa a transferência de estrôncio e consequente de suas assinaturas isotópicas entre os compartimentos da Terra: geosfera, atmosfera, biosfera e hidrosfera (Figura 2) (BATAILLE et al. 2020). O estrôncio presente nos minerais constituintes das rochas é liberado pelo intemperismo para o solo e águas intersticiais, superficiais e subterrâneas, absorvido pela vegetação e animais e incorporado nos esqueletos ósseos (BENTLEY 2006). O estrôncio, dissolvido nas águas dos rios, ingressa nos oceanos

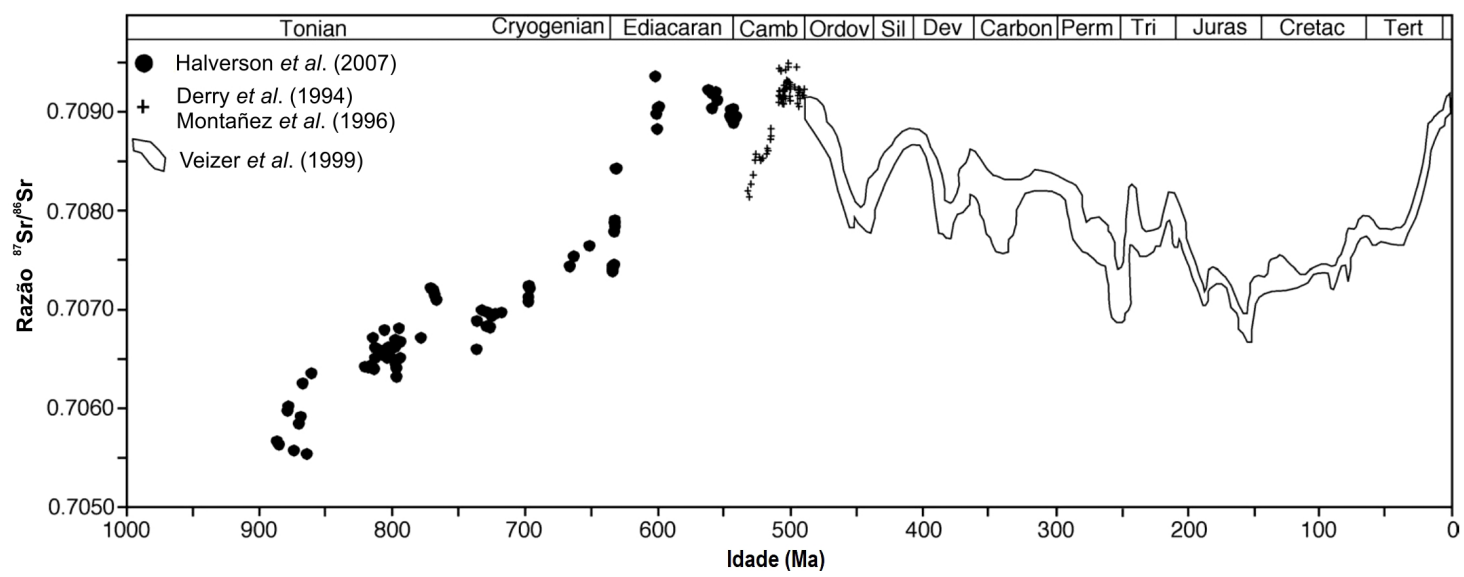

FIGURA 1 - Curva secular para a variação da razão isotópica ${ }^{87} \mathrm{Sr} /{ }^{86} \mathrm{Sr}$ da água do mar, elaborada a partir dos trabalhos de DERRY et al. (1994), MONTAÑEZ et al. (1996), VEIZER et al. (1999) e HALVERSON et al. (2007). Fonte: modificado de HALVERSON et al. (2007). 
através da descarga dos rios no mar, sendo removido pela precipitação de carbonatos marinhos; uma pequena parte é transferida diretamente para atmosfera e, posteriormente, para o continente, pela precipitação (FAURE 1986, CAPO et al. 1998).

Nas rochas, a razão ${ }^{87} \mathrm{Sr} /{ }^{86} \mathrm{Sr}$ varia em função da litologia, mineralogia e idade (MCNUTT 2000). Os minerais em rochas ígneas terão a razão isotópica que corresponde ao ${ }^{87} \mathrm{Sr}$ inicial, presente no magma formador da rocha, somado ao ${ }^{87} \mathrm{Sr}$ gerado pelo decaimento do ${ }^{87} \mathrm{Rb}$, de acordo com o tempo decorrido desde a cristalização dos minerais e da rocha. Os processos metamórficos re-homogeneizam isotopicamente os minerais da rocha e alteram a razão inicial de estrôncio (SHAND et al. 2009). As assinaturas de rochas sedimentares, entretanto, apresentam elevada heterogeneidade, associada à grande variedade de minerais oriundo de diversas rochas com idades diferentes (DA SILVA et al. 2006).
Em solos, as assinaturas são herdadas da rocha-matriz, assim como incorporam assinaturas, por troca iônica ou adsorção, de estrôncio proveniente de águas que percolam o solo (BATAILLE et al. 2020). Grandes diferenças de assinaturas são, portanto, observadas entre solos derivados de rochas com distintas idades (CHADWICK et al. 2009), de diferentes profundidades e de distintos graus de maturação (pouco e muito alterados) (POSZWA et al. 2004).

As plantas absorvem o estrôncio disponível no solo, enquanto os animais obtêm estrôncio por meio de sua dieta alimentar (BENTLEY 2006, GLORENNEC et al. 2016). A variação temporal das assinaturas de estrôncio incorporadas em tecidos animais (p. ex. cabelo, pelos, unhas e dentes) possibilita a reconstrução detalhada da migração de espécies (BRENNAN et al. 2014, VAUTOUR et al. 2015), assim como determina a origem da nu-
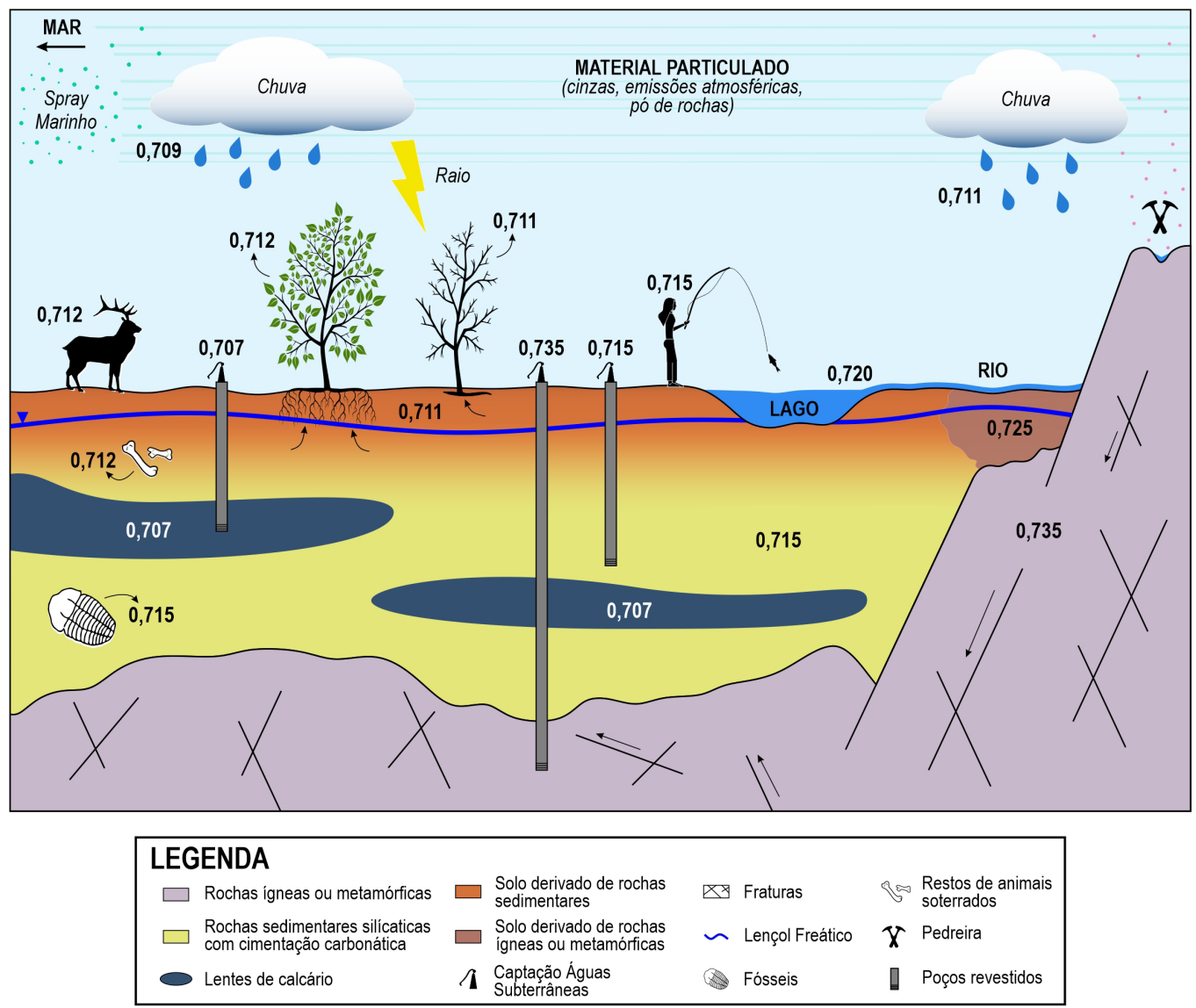

FIGURA 2 - Ciclo geoquímico do estrôncio na geosfera, atmosfera, biosfera e hidrosfera. Os valores da razão ${ }^{87} \mathrm{Sr} /{ }^{86} \mathrm{Sr}$ representam os valores de referência dos distintos substratos. Fonte: inspirado em BATAILLE et al. (2020). 
trição e dessedentação dos animais (BATAILLE et al. 2020).

$\mathrm{Na}$ hidrosfera, as variações na razão isotópica ${ }^{87} \mathrm{Sr} /{ }^{86} \mathrm{Sr}$ estão diretamente associadas aos minerais presentes nas rochas e solos e na eficiência do intemperismo, não sendo alteradas por processos de precipitação mineral e evaporação. $O$ estrôncio é removido das águas como um resultado da precipitação mineral ou de trocas catiônicas (SHAND et al. 2009). A mobilidade do estrôncio em águas possibilita seu uso como traçador de fluxo, pois a exposição de distintos tipos de rocha a processos intempéricos produz distintas assinaturas ${ }^{87} \mathrm{Sr} /{ }^{86} \mathrm{Sr}$ nas águas, constituindo um indicador indireto dos tipos de rocha que foram expostos ao intemperismo químico (FAURE 1986).

Em águas da chuva, as concentrações de estrôncio são baixíssimas e as suas assinaturas isotópicas podem ser associadas à evaporação de águas do mar, spray marinho e a contribuições de partículas carregadas pela atmosfera (poeiras e cinzas) (BANNER 2004). Atividades humanas também podem emitir estrôncio para a atmosfera, tanto na queima de árvores, como em manipulação com as rochas (obras, minerações, indústrias). A contribuição de assinaturas transportadas pela atmosfera, transferidas para a geosfera pela precipitação, pode superar e dominar, em alguns casos, a assinatura isotópica de estrôncio do solo, em diferentes proporções, o que dependerá das taxas de deposição, intemperismo, concentração de estrôncio e razão ${ }^{87} \mathrm{Sr} r{ }^{86} \mathrm{Sr}$ (PETT-RIDGE et al. 2009).

Em águas superficiais, principal fonte de água para os animais, as razões ${ }^{87} \mathrm{Sr} /{ }^{86} \mathrm{Sr}$ refletem a assinatura das rochas da bacia de drenagem e reproduzem sinais isotópicos da origem dos sedimentos e materiais particulados em suspensão (BANNER 2004). Nesse contexto hidrológico, quando associados a dados geoquímicos, principalmente a cátions, os isótopos de estrôncio constituem excelentes indicadores da interação água-rocha, rio-aquífero e da origem da água (BLUM \& EREL 2003, BRENOT et al. 2008, SHAND et al. 2009, PETELET-GIRAUD et al. 2016, BATAILLE et al. 2020).

Nas águas subterrâneas, a razão isotópica ${ }^{87} \mathrm{Sr} /{ }^{86} \mathrm{Sr}$ representa a mistura de fontes com distintas assinaturas isotópicas, podendo ser adquirida tanto durante a recarga diretamente da precipitação, quanto ao longo do fluxo regional, pela interação com o arcabouço geológico do aquífero, incorporando o estrôncio presente nos minerais constituintes da rocha. Nesse sentido, as assinatu- ras isotópicas de estrôncio em águas subterrâneas irão variar em função das diferenças mineralógicas ao longo do fluxo, das características dos processos de dissolução mineral e do tempo de residência (BLUM \& EREL 2003, BANNER 2004, SHAND et al. 2009, XIE et al. 2013).

Para a utilização de isótopos de estrôncio em estudos hidrogeológicos, deve-se considerar alguns aspectos relacionados à água e ao reservatório que constituem informações essenciais para o conhecimento do contexto hidrogeológicos e o levantamento de hipóteses e a interpretação dos resultados isotópicos, a saber: i) a composição química da água; ii) a mineralogia da rocha mãe; iii) a interação água/rocha; iv) o pH da água, temperatura e pressão do sistema; v) as condições da área de estudo (se a evolução hidrogeoquímica está ocorrendo em sistema aberto ou fechado ao $\mathrm{CO}_{2}$ atmosférico) e; vi) características do fluxo, como velocidade e sentido (MCNUTT 2000).

Modelos de mistura, gráficos e modelos probabilísticos são indicados para investigação dos isótopos de estrôncio em águas subterrâneas, uma vez que contribuem na identificação da origem do ${ }^{87} \mathrm{Sr}$. O modelo de mistura simples é o mais frequentemente utilizado, elaborado pela interpolação da razão ${ }^{87} \mathrm{Sr} /{ }^{86} \mathrm{Sr}$ e o inverso da concentração de estrôncio $(1 / \mathrm{Sr})$, pois auxilia na interpretação de relações hidrogeológicas e na dedução de processos de intemperismo dominantes, assim como no reconhecimento de misturas e suas proporções relativas, quando formada uma linha reta entre dois end-members (SHAND et al. 2009) (Figura 3).

Modelos de mistura probabilísticos, em contexto Bayesiano, são indicados para contextos hidrogeológico complexos, que possuem múltiplas fontes, em que se busca quantificar proporções de contribuição de cada end-member (PARNELL et al. 2013, PHILLIPS et al. 2014) (Figura 4). Os resultados do modelo irão depender diretamente da qualidade dos dados, das hipóteses do modelo, do conhecimento do sistema e reconhecimento das limitações da modelagem (PHILLIPS et al. 2014). Nesse sentido, modelos de misturas Bayesianos que incluem isótopos de estrôncio, a partir da incorporação de valores da razão ${ }^{87} \mathrm{Sr} r{ }^{86} \mathrm{Sr}$ e concentração de estrôncio no modelo, são pioneiros em estudos hidrogelógicos (MAILLOUX et al. 2014, MEGHDADI \& JAVAR 2018, QUAGGIO 2021). Para o cálculo de modelo de mistura Bayesiano sugere-se o pacote de mistura de isótopos estáveis, nomeado simmr - Stable Isotope Mixing Models in $R$ (PARNELL \& INGER 2021), a ser executa- 


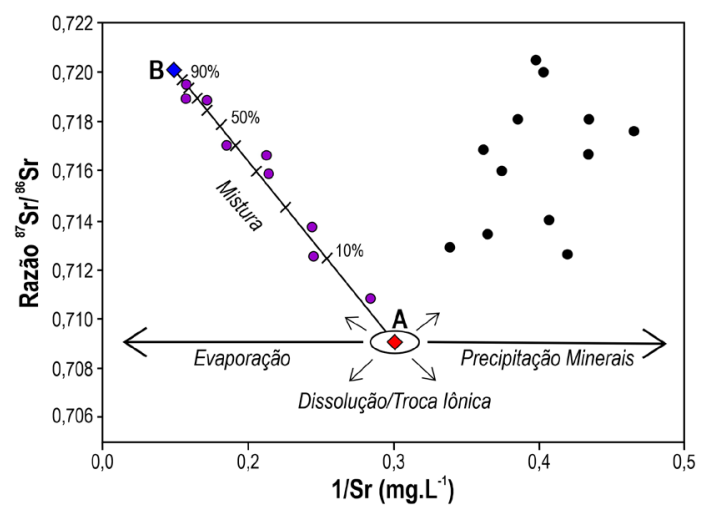

FIGURA 3 - Modelo de mistura simples teórico, a partir da interpolação da razão ${ }^{87} \mathrm{Sr} /{ }^{86} \mathrm{Sr}$ e o inverso da concentração de estrôncio (1/Sr). Uma mistura hipotética ideal, de um end-member A (vermelho) com um end-member B (azul), será representada por uma linha reta e as assinaturas produtos da mistura estarão sobre e próximo a ela (pontos roxos). Além da mistura, outros processos podem alterar a razão ${ }^{87} \mathrm{Sr} /{ }^{86} \mathrm{Sr}$ e a concentração de estrôncio (pontos pretos). Fonte: elaborado a partir de SHAND et al. (2009).

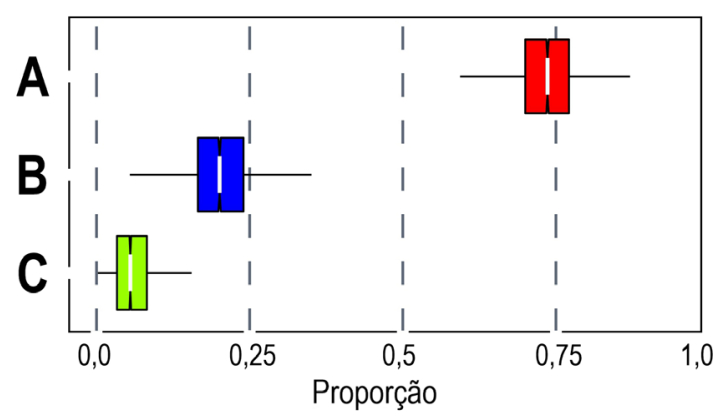

FIGURA 4 - Modelo de mistura Bayesiano teórico. A partir de um banco de dados de águas subterrâneas e end-members A-B-C hipotéticos, que possuem valores das razões ${ }^{87} \mathrm{Sr} /{ }^{86} \mathrm{Sr}$ e concentrações de estrôncio, o modelo retorna à proporção da contribuição dos end-members (caixas) e o desvio-padrão (hastes). Neste caso hipotético, o modelo demonstra que a contribuição do end-member A é dominante sobre as assinaturas isotópicas de estrôncio.

do no software R Studio (R CORETEAM 2021). O pacote simmr constitui uma extensão (pacote) do software R Studio, com o objetivo de solucionar equações de mistura, utilizando isótopos estáveis, de maneira mais sofisticada, com interface mais simples ao usuário e opções gráficas mais avançadas do que seu antecessor (PARNELL \& INGER 2021), o SIAR - Stable Isotope Analysis in $R$ (PARNELL \& JACKSON 2013).

\section{PROCEDIMENTOS DE AMOSTRAGEM E TÉCNICAS ANALÍTICAS PARA ESTUDOS HIDROGEOLÓGICOS}

\subsection{Procedimentos de amostragem}

A coleta de amostras de águas subterrâneas consiste na atividade mais importante em levantamentos hidroquímicos e isotópicos, especialmente para a determinação da razão isotópica ${ }^{87} \mathrm{Sr} /{ }^{86} \mathrm{Sr}$, em que os cuidados relativos ao armazenamento e preservação das amostras podem representar a diferença na qualidade dos resultados obtidos. As amostras devem ser coletadas preferencialmente nos cavaletes dos poços e, quando não for possível, coletadas antes dos pontos de chegada da água no reservatório ou do ponto onde é efetuada adição de produtos químicos na água, como cloro e flúor, de maneira a garantir que as amostras representem apenas o aquífero.

$\mathrm{O}$ procedimento de amostragem, visando a determinação da razão ${ }^{87} \mathrm{Sr} /{ }^{86} \mathrm{Sr}$ em águas subterrâneas, compõe uma séria de etapas, que devem ser seguidas com rigor, e são descritas em detalhes por MARTINS et al. (2008). Os frascos escolhidos para a coleta devem ser de material inerte, como o polietileno, com tampa rosqueada, ambos incolores. Na coleta, a amostra deve ser filtrada in situ com filtro de acetato de celulose de porosidade de $45 \mu \mathrm{m}$. Após a filtragem, o frasco de coleta deve ser lavado no mínimo duas vezes com a amostra filtrada, antes da coleta da alíquota que será analisada. As amostras devem ser acidificadas com ácido nítrico (concentrado) de pureza analítica e destilado, para diminuir o $\mathrm{pH}$ entre 1-3 e manter o estrôncio em solução (MARTINS 2008). As amostras devem, obrigatoriamente, ser mantidas em armazenamento refrigerado até a análise.

Para a interpretação dos resultados dos isótopos de estrôncio em águas subterrâneas, é crucial a avaliação de dados hidroquímicos e dados construtivos dos poços, para definir possíveis origens de assinaturas, que também podem ser alteradas localmente por características individuais dos poços. Sempre que disponível, é importante avaliar informações referentes ao perfil estratigráfico, profundidade de perfuração e de captação, revestimento, tipo do poço (tubular, escavado, etc.) e demais informações que possam contribuir na determinação de fontes locais de ${ }^{87} \mathrm{Sr}$. O ideal é coletar amostras representativas dos aquíferos explotados, sem interferências e misturas, e 
das possíveis fontes do contexto hidrogeológico em questão, como águas superficiais, precipitação e rocha-matriz, possíveis end-members de modelos de mistura.

\subsection{Técnicas analíticas}

A única forma de se determinar razões isotópicas é a partir de espectrômetros de massa, por serem os únicos equipamentos com capacidade de determinar com alta precisão a razão de abundâncias de isótopos individualmente e de produzirem um limite de detecção extremamente baixo (POTTS 1992). Um espectrômetro de massas não mede massas, mas mede razões massa-carga ou $\mathrm{m} / \mathrm{z}$, dos íons do material analisado, usando um campo magnético ou elétrico, ou ainda uma combinação dos dois (GREAVES \& ROBOZ 2014). Os espectrômetros de massa são compostos por três componentes: i) fonte de íons, onde as amostras são ionizadas; ii) ímãs, responsáveis pela formação dos campos magnéticos e deflexão que separa os íons pelas suas massas; iii) coletores, compostos por copos de faraday, que coletam as cargas de cada íon e as convertem em uma corrente elétrica (ALLÈGRE 2008).

O material a ser analisado deve ser ionizado em uma câmara à vácuo. A ionização pode ser por: i) aquecimento, através de corrente elétrica, de filamento de tântalo, ou rênio, sobre o qual foi depositada a amostra, sendo conhecida como espectrometria de massa por ionização térmica (TIMS - Thermal Ionization Mass Spectrometry); ou ii) plasma de argônio, gerado quando energia é acoplada ao gás, através de uma bobina de indução (ICP - Inductively Coupled Plasma). As altas temperaturas do plasma ionizam o gás argônio que captura elétrons menos firmemente ligados dos íons das amostras, assim as ionizando (ALBARÈDE 2011). Para análises isotópicas de estrôncio, recomenda-se o TIMS, uma vez que o gás argônio utilizado no ICP pode conter traços de criptônio (possui isótopo de massa 86) e interferir na leitura do sinal do estrôncio.

Além dos espectrômetros de massa, é necessário separar o elemento de interesse, para eliminar massas interferentes no espectrômetro. Essa separação é feita em laboratório químico, com controle de ar e pressão, através de resina de troca iônica. Essa resina é um substrato sólido, que cria um ambiente que retem os elementos de interesse e os libera, de acordo com os reagentes que são utilizados. No caso do estrôncio a resina utilizada é a Sr Spec da Eichron. Todo o conjunto de amostras deve incluir as análises de brancos do laboratório (reagentes) e de padrões reconhecidos internacionalmente, como o padrão NBS SRM 987 (BANNER 2004), entre outros, para garantir que os dados produzidos sejam confiáveis.

Os resultados dos espectrômetros são obtidos a partir de análise estatística de 100 leituras de razões isotópicas, com intervalo de confiança de $95 \%$. Possíveis fracionamentos dos isótopos de estrôncio, durante o processo de ionização, são corrigidos pela normalização das assinaturas para ${ }^{86} \mathrm{Sr} /{ }^{88} \mathrm{Sr}=0,1194$. O detalhamento passo a passo de procedimentos analíticos, específicos para determinação dos isótopos de estrôncio em águas naturais, podem ser encontrados nos trabalhos de BORDALO et al. (2007), MARTINS (2008) e MARTINS et al. (2008).

Apesar de ser necessária uma infraestrutura cara e robusta para a realização dessas análises, o que torna este dado mais caro de se obter, quando comparado com análises químicas elementares, os isótopos tem conquistado cada vez mais espaço em estudos hidrogeológicos.

\section{APLICAÇÃO DOS ISÓTOPOS DE ESTRÔNCIO EM ÁGUAS SUBTERRÂNEAS}

Estudos hidrogeológicos que utilizam os isótopos de estrôncio no Brasil são escassos, apesar da versatilidade da técnica e do crescimento desta linha de pesquisa no cenário internacional (Figura 5A-B). As primeiras publicações, relacionadas ao emprego de isótopos de estrôncio na hidrogeologia, são do começo dos anos 1970 (STUEBER et al. 1972, 1975; STEELE \& PUSHKAR 1973). O menor avanço da linha de pesquisa deste isótopo radiogênico na hidrogeologia no Brasil é associado à dificuldade no acesso à tecnologia analítica necessária para determinação dos isótopos de estrôncio e o desconhecimento de sua aplicação. No Brasil, os primeiros trabalhos que determinaram os isótopos de estrôncio em etapas do ciclo hidrológico surgiram na década de 1990, sendo o estudo pioneiro o realizado nas águas do Rio Tocantins no Pará, que buscou quantificar as contribuições atmosféricas e entender o intemperismo químico ao longo do rio (HIERONYMUS et al. 1993). Observa-se que, desde as pioneiras pesquisas hidrogeológicas brasileiras, a razão ${ }^{87} \mathrm{Sr} /{ }^{86} \mathrm{Sr}$ foi utilizada, em sua maioria, na determinação das fontes de estrôncio em águas subterrâneas e, secundariamente, na descrição das interações água-rocha, em conjunto com outros traçadores isotópicos (Figura 5C). 
A aplicação dos isótopos de estrôncio em águas subterrâneas em território brasileiro inclui, em sua maioria, estudos locais, principalmente no estado de São Paulo. Estudos regionais foram realizados apenas na Bacia Sedimentar do Paraná. Na sequência, é apresentada uma breve revisão desses estudos com destaque aos resultados e interpretações obtidas. A compilação da razão ${ }^{87} \mathrm{Sr} /{ }^{86} \mathrm{Sr}$, a concentração de estrôncio e detalhes dos métodos analíticos empregados nos estudos brasileiros de águas subterrâneas revisados é exposto no Anexo I. Todos os estudos utilizaram o modelo de mistura simples, apenas QUAGGIO (2021) incluiu também o modelo de mistura Bayesiano em sua avaliação.

\subsection{Bacia Sedimentar do Paraná}

A Bacia Sedimentar do Paraná representa uma bacia intracratônica, constituída por uma sucessão vulcano-sedimentar com idades entre o Neo-Ordoviciano e o Neocretáceo (MILANI \& RAMOS 1998, MILANI 2004), de ocorrência na América do Sul, abrangendo territórios do sul do Brasil, leste do Paraguai, nordeste da Argentina e norte do Uruguai, com área aproximada de 1,7 milhões de quilômetros quadrados (HOLZ et al. 2010). São reconhecidas na Bacia do Paraná seis unidades de escala regional, conhecidas como supersequências, que podem ser categorizadas em dois grupos: as superquências do Rio Ivaí (Ordoviciano-

\section{(A) Publicações em revistas internacionais por ano}

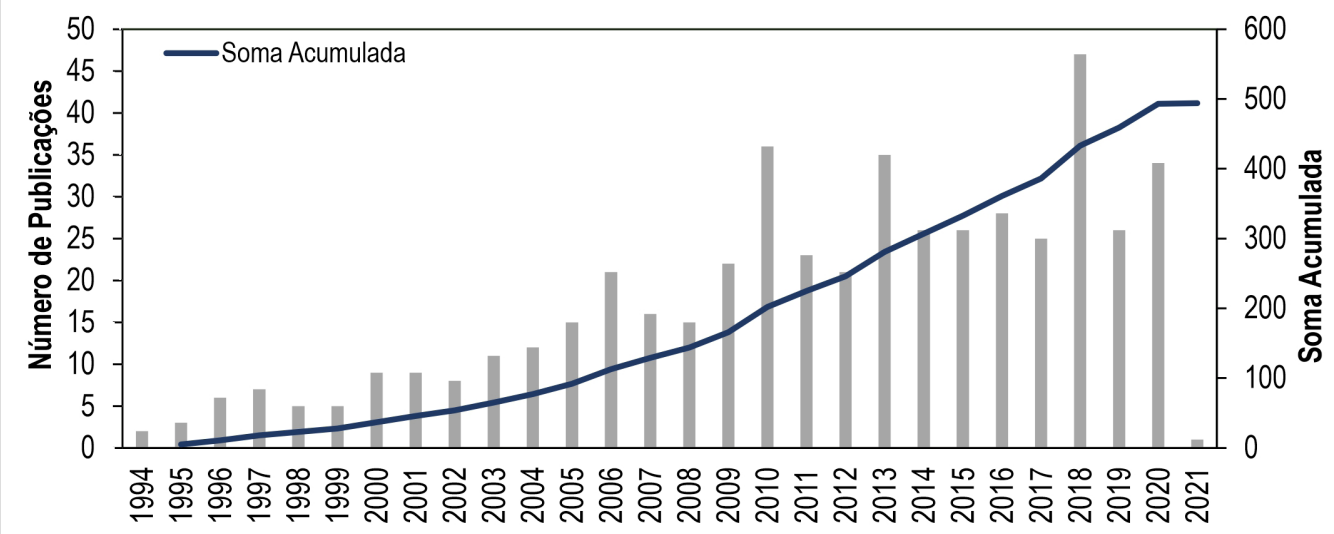

Ano de Publicação

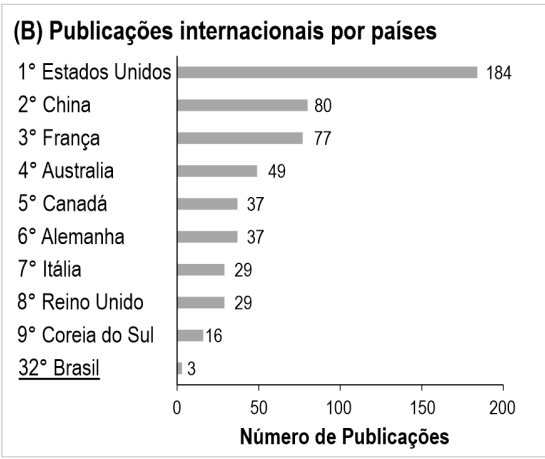

(C) Publicações brasileiras divididas por:

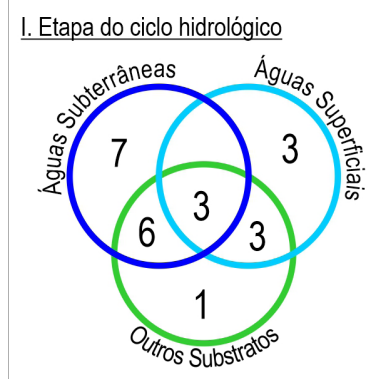

II. Traçador isotópico utilizado

FIGURA 5 - Avaliação das publicações internacionais sobre isótopos de estrôncio em estudos hidrogeológicos desde 1994 (A) e os países de origem desses estudos (B), segundo base de dados Scopus, que inclui somente publicações de alcance internacional, acessada em 16/09/2020. (C) Quantidade de pesquisas (teses, artigos e levantamentos técnicos) hidrogeológicas brasileiras, que utilizaram isótopos de estrôncios (C.I) em distintas etapas do ciclo hidrológico e (C.II) em conjunto com outros traçadores isotópicos. Outros substratos incluem a determinação das razões ${ }^{87} \mathrm{Sr} /{ }^{86} \mathrm{Sr}$ em águas da chuva, rochas, sedimentos e espeleotemas. Outros isótopos incluem os de boro $(\mathrm{B})$, carbono $(\mathrm{C})$, chumbo $(\mathrm{Pb})$, neodímio $(\mathrm{Nd})$, radônio $(\mathrm{Ra})$, rubídio $(\mathrm{Rb})$, samário $(\mathrm{Sm})$ e urânio (U). Os estudos brasileiros avaliados foram encontrados em repositórios de universidades, revistas cientificas brasileiras e internacionais e bases de dados de órgãos públicos. 
Siluriano), Paraná (Devoniano) e Gondwana I (Carbonífero Eotriássico), que representam sucessões sedimentares dos ciclos transgressivo-regressivos relacionados ao nível relativo do mar durante o Paleozoico; e as supersequências do Gondwana II (Meso a Neotriássico), Gondwana III (NeojurássicoEocretáceo) e Bauru (Neocretáceo), que correspondem aos pacotes de rochas sedimentares continentais associados a rochas ígneas (MILANI 1997, MILANI et al. 2007).

Os sistemas aquíferos da Bacia do Paraná são considerados como os mais promissores do Brasil (BRASIL 2007), associados a elevada produtividade de águas subterrâneas, constituindo importante fonte de águas de qualidade para o abastecimento da população e de atividades industriais e agrícolas. As unidades aquíferas da Bacia do Paraná, de idade Mesozoica, são o Sistema Aquífero Bauru (SAB), associadas aos sedimentos do Grupo Bauru; o Sistema Aquífero Serra Geral (SASG), associado aos basaltos da Formação Serra Geral; o Sistema Aquífero Guarani (SAG), associado aos arenitos das formações Botucatu e Piramboia; e, no estado de São Paulo, as unidades Permo-Carboníferas do Sistema Aquífero Tubarão (SAT) e o Sistema Aquífero PréCambriano (SAPC), sotoposto, associado ao embasamento cristalino Pré-Cambriano.

\subsubsection{Sistema Aquífero Pré-Cambriano}

Em diferentes localidades da região de Itu, REYES (2009) determinou a razão ${ }^{87} \mathrm{Sr}{ }^{86} \mathrm{Sr}$ nas águas subterrâneas do SAPC, em poços que cortam os granitos da Suíte Intrusiva Itu. Os perfis dos poços indicaram a existência de dois tipos de granitos, um rosa e um cinza, provavelmente de mineralogia distinta, com a presença de feldspatos potássicos-sódicos nos granitos rosa. As águas subterrâneas que circulam pelo granito cinza apresentaram razões isotópicas entre 0,71024-0,71171 em Itupeva, 0,715650,71622 em Salto e 0,71561-0,73379 em Itu, enquanto o granito rosa, em Indaiatuba, teve razão entre $0,72161-0,73863$. Segundo a autora, as razões muito radiogênicas derivam de rochas hospedeiras com elevadas concentrações de potássio e rubídio, associadas a um sistema de recarga baixo ou nulo.

\subsubsection{Sistema Aquífero Guarani}

O SAG é o aquífero que possui maior disponibilidade de dados isotópicos de estrôncio no Brasil. As primeiras determinações da razão isotópica ${ }^{87} \mathrm{Sr} /{ }^{86} \mathrm{Sr}$ no $\mathrm{SAG}$, em levantamentos técnicos regionais, foram realizadas no âmbito do "Projeto de Proteção Ambiental e Desenvolvimento Sustentável do Sistema Aquífero Guarani (PSAG)", executado pela OEA (Organização dos Estados Americanos), entre os anos de 2003 e 2008 (OEA 2009); e, complementar ao PSAG, em um estudo voltado a determinação da vulnerabilidade natural das áreas de afloramento do SAG, conduzido pela Agência Nacional de Águas (ANA) (ANA 2016). Entretanto, apesar do banco de dados disponível, as razões isotópicas ${ }^{87} \mathrm{Sr} /{ }^{86} \mathrm{Sr}$ não foram extensivamente exploradas.

No SAG, os isótopos de estrôncio também foram utilizados por BONOTTO \& ELLIOT (2017), em conjunto com dados hidroquímicos, elementos de terras-raras e isótopos de boro ao longo de uma linha de fluxo cortando o estado de São Paulo, de direção $\mathrm{E}-\mathrm{W}$, em águas hipertermais $\left(>38^{\circ} \mathrm{C}\right)$ e águas frias/hipotermais (entre 25 e $33^{\circ} \mathrm{C}$ ). As razões isotópicas de ${ }^{87} \mathrm{Sr} /{ }^{86} \mathrm{Sr}$ em água hipertermais do SAG são similares entre si (0,7088-0,7099), enquanto distintas razões isotópicas de ${ }^{87} \mathrm{Sr} r{ }^{86} \mathrm{Sr}$ são encontradas em águas frias (em torno de 0,7072) e hipotermais $(0,7117-0,7130)$. Os autores concluíram que a variação da assinatura isotópica do estrôncio nas águas hipertermais pode ser atribuída ao processo de dessorção nos minerais de argila sob altas temperaturas, enquanto nas águas frias/ hipotermais, mais enriquecidas em ${ }^{87} \mathrm{Sr}$ radiogênico, estaria associada à lixiviação da segunda fase da calcita, presente no cimento dos arenitos das formações Botucatu e Piramboia.

Posteriormente, QUAGGIO (2021) compilou os dados de isótopos de estrôncio no SAG e agregou novas determinações, na porção Norte do aquífero, abrangendo os estados do Paraná (PR), São Paulo (SP), Goiás (GO), Mato Grosso (MT), Mato Grosso do Sul (MS) e Minas Gerais (MG), propondo um modelo de mistura, calculado em contexto Bayesiano, a partir da distribuição espacial das razões ${ }^{87} \mathrm{Sr} /{ }^{86} \mathrm{Sr}$ entre águas do SAG, águas meteóricas e águas das unidades PÓS e PRÉ-SAG. No SAG, próximo às zonas de afloramento, em águas de tipologia $\mathrm{HCO}_{3}-\mathrm{Ca}$, as assinaturas ${ }^{87} \mathrm{Sr} /{ }^{86} \mathrm{Sr}$ são mais variáveis, com valores mais radiogênicos associados à maior proporção de águas do SAG $(0,71122-0,71734)$, menos radiogênicos, à maior contribuição de águas das unidades PÓS-SAG $(0,70705-0,7069)$, e pouco radiogêni$\cos (0,7088-0,71072)$, à contribuição de águas das unidades PRÉ-SAG e a águas meteóricas. Em uma zona de transição, entre porções livres e confinadas, em águas $\mathrm{HCO}_{3}-\mathrm{Na}$, as razões são menos variáveis $(0,70875-0,71341)$ e é identificada a contri- 
buição de águas das unidades PRÉ e PÓS-SAG; na zona confinada, em águas $\mathrm{SO}_{4}-\mathrm{Cl}-\mathrm{Na}$, onde não há mais a contribuição de águas meteóricas e das unidades PÓS-SAG, as assinaturas são mais homogêneas $(0,70913-0,71070)$ e associadas à contribuição de águas das unidades PRÉ-SAG.

\subsubsection{Sistema Aquífero Serra Geral}

Apenas o estudo publicado por INNOCENT et al. (1997) fez uso dos isótopos de estrôncio no SASG, com determinação da razão ${ }^{87} \mathrm{Sr} /{ }^{86} \mathrm{Sr}$ em águas subterrâneas e superficiais, bem como em rochas, para investigação da interação água-rocha nos basaltos da Formação Serra Geral, na cidade de Ribeirão Preto (SP). Nas águas subterrâneas de um mesmo poço, os autores observam que a razão ${ }^{87} \mathrm{Sr} /{ }^{86} \mathrm{Sr}$ apresenta assinaturas entre $0,7066-0,7072$ na profundidade dos basaltos (entre $140-200 \mathrm{~m}$ ) e de 0,717 na transição entre os basaltos e os arenitos associados a unidades do SAG. Associando aos valores encontrados nas amostras de rochas, os autores concluem que a maior parte do estrôncio nas rochas é removido durante os primeiros estágios de intemperismo, existindo uma tendência de aumento das razões ${ }^{87} \mathrm{Sr} /{ }^{86} \mathrm{Sr}$ com o aumento das fácies intemperizadas, ou com a entrada de águas de chuvas radiogênicas e interação das águas com os arenitos e minerais residuais ou neoformados.

\subsubsection{Sistema Aquífero Bauru}

Os isótopos de estrôncio, em conjunto com os de oxigênio e hidrogênio, foram utilizados nas águas subterrâneas do SAB por CRESPI (2013) na investigação das anomalias de Bário nas unidades aquíferas Adamantina e Marília na cidade de Gália (SP). A autora determinou valores da razão ${ }^{87} \mathrm{Sr} /{ }^{86} \mathrm{Sr}$ de $0,7090-0,7093$ para as águas subterrâneas do $\mathrm{SAB}$, semelhante às assinaturas dos arenitos carbonáticos (0,7085-0,7090), lixiviados em laboratório a partir de rochas do aquífero. Dessa forma, concluiu-se que as anomalias de bário são de origem geogênica, associadas aos carbonatos, enquanto a assinatura isotópica de estrôncio das águas subterrâneas do $\mathrm{SAB}$ representa a recarga e lixiviação de fases minerais do arcabouço geológico do aquífero.

Em Urânia (SP), MALDANER et al. (2013) aplicaram os isótopos de estrôncio, em conjunto com a descrição hidroquímica das águas subterrâneas, na unidade aquífera Adamantina. As águas subterrâneas foram classificadas em três zonas: Rasa (até $30 \mathrm{~m}$ ), com fácies $\mathrm{Cl}_{-} \mathrm{NO}_{3}-\mathrm{Ca}-\mathrm{Mg}$ para
Cl- $\mathrm{NO}_{3}-\mathrm{Na}$, Intermediária (de 30-70 m), com fácies $\mathrm{HCO}_{3}-\mathrm{NO}_{3}-\mathrm{Ca}-\mathrm{Mg}$, e Profunda (acima de 70 $\mathrm{m}$ ), com fácies $\mathrm{HCO}_{3}-\mathrm{Na}$. As assinaturas isotópicas de estrôncio variam entre 0,7085-0,7137 e apresentam diminuição gradual com o aumento da profundidade. Segundo os autores, a variação da razão ${ }^{87} \mathrm{Sr} /{ }^{86} \mathrm{Sr}$ é devida primeiramente à interação água-rocha, associada à presença de diferentes rochas ou assinaturas especificas de minerais afetados por forte intemperismo próximo a superfície, e, secundariamente, à recarga.

\subsection{Bacia do Alto Tietê}

A Bacia do Alto Tietê abriga o maior pólo econômico do país e elevada densidade populacional, a Região Metropolitana de São Paulo (RMSP), onde são reconhecidos dois sistemas aquíferos principais: o Sistema Aquífero Cristalino (SAC), associado ao embasamento Pré-Cambriano, e o Sistema Aquífero Sedimentar (SAS), associado aos sedimentos do Grupo Taubaté (HIRATA \& FERREIRA 2001). Neste contexto, os isótopos de estrôncio foram utilizados como traçador da recarga e contaminação das águas subterrâneas, em conjunto com outros traçadores isotópicos e técnicas hidroquímicas.

Utilizando os isótopos de estrôncio, em conjunto com isótopos de chumbo, oxigênio e hidrogênio, em amostras de águas subterrâneas, meteóricas e de rochas, MARTINS (2008) descreveu os mecanismos de recarga e contaminação das águas subterrâneas em duas áreas na Bacia do Alto Tietê: i) Vila Eutália, na Zona Leste da Cidade; e ii) Cidade Universitária (USP), na Zona Oeste de São Paulo. Na Zona Leste, a autora identificou quatro grupos hidroquímicos, dois mais contaminados com cloreto e nitrato, um sem indícios de contaminação e um intermediário. As composições isotópicas de estrôncio das amostras de água subterrânea indicaram mistura de assinatura entre águas de chuva $(0,710$ e 0,717$)$ e as rochas $(0,730$ a 0,780$)$, sendo que algumas amostras de água subterrânea contaminada tiveram assinaturas semelhantes à água de abastecimento $(0,714)$, indicando essas águas como potenciais fontes de recarga. Na Zona Oeste, área com mais cobertura vegetal, favorecendo a infiltração da água de chuva $(0,713$ a 0,717$)$, as amostras de água subterrânea apresentaram composição isotópica de estrôncio mais próximas às da chuva do que das rochas, mas também indicaram uma mistura entre chuva e estrôncio das rochas $(0,717$ a 0,777$)$. As amostras de água de abastecimento também apresentaram ra- 
zões ${ }^{87} \mathrm{Sr} /{ }^{86} \mathrm{Sr}$ semelhantes às amostras de águas subterrâneas $(0,714)$. Os resultados indicaram que provavelmente, havia mais uma fonte, para explicar a composição isotópica de algumas amostras, mas que não foi previamente identificada e analisada. Esses resultados indicaram que as razões isotópicas de estrôncio podem servir para complementar a identificação de diferentes fontes de recarga e contaminação.

PINO (2009), por sua vez, avaliou a origem das anomalias de flúor observadas no Bairro da Barra Funda, Zona Oeste da RMSP, a partir da combinação da hidroquímica das águas subterrâneas com os isótopos de estrôncio, oxigênio e hidrogênio. A autora determinou razões ${ }^{87} \mathrm{Sr} /{ }^{86} \mathrm{Sr}$ entre 0,713-0,716 para o SAS, mais raso, cujas assinaturas se assemelham às determinadas no solo; e razões entre $0,722-0,726$ para o SAC, mais profundo (150-450 m). De maneira geral, a ocorrência de flúor está associada às assinaturas de estrôncio correspondentes às rochas do $\mathrm{SAC}$, mas em algumas ocorrências isso não acontece. Segundo a autora, a origem das elevadas concentrações de flúor é estritamente natural, associada a minerais portadores de flúor em maiores profundidades, onde há fraturas previamente preenchidas por fluidos hidrotermais com formação de pegmatitos, e associada também a um controle estrutural em uma faixa de direção WNW-ESSE no centro da área de estudo. Este controle é devido à presença de uma depressão no embasamento, onde há falhas que contribuem para a percolação destes fluídos hidrotermais. Nestas porções, são observadas maiores concentrações de flúor, assinaturas isotópicas de ${ }^{18} \mathrm{O}$ $\mathrm{e}^{2} \mathrm{H}$ mais enriquecidas, maiores razões ${ }^{87} \mathrm{Sr} r{ }^{86} \mathrm{Sr}$ e maiores espessuras do SAS sobre o SAC.

\subsection{Sistemas Aquíferos Costeiros}

Nos sistemas aquíferos costeiros brasileiros, localizados na região Norte e Nordeste do país, a aplicação dos isótopos de estrôncio busca compreender processos de salinização e mistura com águas de origem marinha. Em geral, os estudos são de escala local, nos estados do Ceará, Pará e Pernambuco.

\subsubsection{Ceará}

No estudo de caso de FRISCHKORN et al. (2002), foi avaliada a origem das águas do lençol freático no embasamento cristalino, onde afloram rochas gnáissicas e graníticas, na cidade de Fortaleza (CE). Os autores demonstraram, a partir da assinatura isotópica de estrôncio, que no aquífero raso de Fortaleza (0,70933-0,71921) há pontos que recebem contribuição de águas de fuga da rede de abastecimento, infiltradas no aquífero através de fossas, cuja assinaturas se assemelham às das rochas graníticas mais radiogênicas presentes no reservatório de origem $(0,7165-0,7188)$, e pontos com contribuições de intrusões salinas da água do mar, próximo à costa.

\subsubsection{Pará}

Buscando estabelecer um procedimento analítico para determinação da razão ${ }^{87} \mathrm{Sr} /{ }^{86} \mathrm{Sr}$ em águas naturais, BORDALO et al. (2007) utilizaram águas subsuperficiais da zona costeira da região de Bragantina (PA). Os autores avaliaram águas de três pontos, com distintas condições construtivas: i) um poço do tipo amazonas, que capta águas armazenadas na Formação Barreiras, com razão ${ }^{87} \mathrm{Sr} /{ }^{86} \mathrm{Sr}$ entre $0,71027-0,71364$, sendo representativo de águas exclusivamente continentais; ii) águas de um piezômetro, em área de mangue intermaré do Furo do Chato, com razão ${ }^{87} \mathrm{Sr} /{ }^{86} \mathrm{Sr}$ entre 0,70903-0,70933, que apresentam clara influência de águas marinhas $(0,709)$; iii) águas de um poço tubular perfurado em ambiente de pântano salino, com razão ${ }^{87} \mathrm{Sr} r{ }^{86} \mathrm{Sr}$ entre $0,70959-0,70984$, que representa um cenário intermediário entre os outros dois pontos, com influência limitada da água do mar e uma pequena contribuição de fonte mais radiogênica.

Na Região Metropolitana de Belém (RMB), OLIVEIRA FILHO \& GALARZA (2013) buscaram identificar a mistura entre os dois principais reservatórios de águas subterrâneas, o Sistema Aquífero Barreiras (SABR) e o sotoposto Sistema Aquífero Pirabas (SAP), a partir das características hidroquímicas e assinaturas isotópicas de estrôncio. Para tanto, os autores avaliaram a variação sazonal das razões ${ }^{87} \mathrm{Sr} /{ }^{86} \mathrm{Sr}$ e observaram maior homogeneização das razões no período chuvoso, devido à maior contribuição de águas meteóricas. Nas águas subterrâneas do SABR, onde predominam os íons $\mathrm{Cl}^{-}$e $\mathrm{Na}^{+}$, as razões ${ }^{87} \mathrm{Sr} /{ }^{86} \mathrm{Sr}$ variam entre 0,70591-0,71979 no período seco e entre 0,705810,71621 no período chuvoso; no SAP, onde predominam os íons $\mathrm{HCO}_{3}{ }^{-} \mathrm{e} \mathrm{Ca}^{2+}$, as razões variam entre 0,70857-0,71093 no período seco e entre 0,708230,70948 no período chuvoso. Segundo os autores, as assinaturas do SABR são mais radiogênicas devido à maior presença de rochas ricas em feldspatos, e sugerem que a mistura de águas subterrâneas entre os sistemas aquíferos é maior durante o pe- 
ríodo chuvoso (OLIVEIRA FILHO \& GALARZA 2013).

DA SILVA (2015) utilizou metodologia semelhante à de OLIVEIRA FILHO \& GALARZA (2013), visando caracterizar a hidroquímica e detectar a mistura de águas subterrâneas, a partir dos isótopos de estrôncio, no SABR e SAP superior nos municípios de Castanheiras e Santa Maria do Pará. O autor determinou razões ${ }^{87} \mathrm{Sr} /{ }^{86} \mathrm{Sr}$ para o SABR entre 0,71271-0,72388 no período seco e 0,70423-0,70995 no período chuvoso, enquanto para o SAP, entre $0,70608-0,709063$ no período seco e 0,70571-0,70927 no período chuvoso. A origem marinha das rochas do SAP é identificada como responsável pela pouca variação das assinaturas isotópicas de estrôncio nos dois períodos, próximas a valores da água do mar, havendo ainda contribuição de águas meteóricas que infiltram através do SABR. No SAP, as amostras mais radiogênicas do período seco são associadas à interação água-rocha, devido à semelhança com assinaturas de rochas da Formação Barreiras; no período chuvoso, a brusca diminuição de assinaturas sugere um processo de homogeneização promovido pelo maior volume de entrada de águas meteóricas e pela mistura de águas do SABR com águas do SAP (DA SILVA 2015).

\subsubsection{Pernambuco}

A Região Metropolitana de Recife (RMR), na costa do estado do Pernambuco, é uma região com elevada densidade populacional, cujos problemas relacionados à água são críticos e diversos, associados aos impactos causados pela super explotação e salinização das águas subterrâneas. Na RMR, ocorrem cinco principais sistemas aquíferos: em subsuperfície, os Sistemas Aquíferos Boa Viagem (SABV) e Barreiras (SABR), livres e expostos à contaminação; o Sistema Aquífero Beberibe (SABB), semi-confinado, localizado na porção norte de Recife; o Sistema Aquífero Cabo (SACB), confinado, localizado na porção sul de Recife; e o embasamento cristalino das bacias da Paraíba e de Pernambuco (LEAL 1994).

Neste complexo contexto hidrogeológico, CARY et al. (2015) realizaram uma análise multi-isotópica, que contou com a aplicação de isótopos de estrôncio, boro, oxigênio e hidrogênio, para compreender a relação entre os sistemas aquíferos da RMR e a origem da salinização nas águas subterrâneas. Em relação aos isótopos de estrôncio, na porção norte da área de estudo, as assinaturas isotópicas das águas subterrâneas do SABB, indicaram misturas entre as rochas do embasamento $(0,721$ a 0,755$)$, águas superficiais da estação de tratamento de água e rios $(0,713-0,719)$ e água do mar $(0,709)$. Ao sul da área de estudo, as razões ${ }^{87} \mathrm{Sr} /{ }^{86} \mathrm{Sr}$ das águas subterrâneas do $\mathrm{SACB}$ $(0,7097-0,7141)$ provêm da interação água-rocha com os sedimentos deltaicos da Formação Cabo e da contribuição mais radiogênica das águas do embasamento da Bacia de Pernambuco. Por outro lado, também reflete a mistura da água do mar com as águas superficiais, podendo ter influência de águas associadas a paleomangues. A assinatura das águas do SABR $(0,71396-0,71861)$, posicionado acima do SABB e SACB, representam a heterogeneidade das rochas da Formação Barreiras. As razões ${ }^{87} \mathrm{Sr} r{ }^{86} \mathrm{Sr}$ nas águas do SABV estão divididas em dois grupos: TQ1 $(0,70925-0,72189)$ e TQ2 $(0,7139-0,7186)$. As assinaturas isotópicas do grupo TQ1, com razões menos radiogênicas e moderadas concentrações de cloreto, se originam da dissolução dos carbonatos presentes nas formações Estiva, Gramame e Maria Farinha, ou de formações carbonáticas que liberam estrôncio com assinatura isotópica próxima da do mar durante as transgressões marinhas pleistocênicas e holocênicas. Neste caso, não se pode diferenciar as assinaturas isotópicas de estrôncio relacionadas à intrusão marinha e a dissolução de carbonatos. No grupo TQ2, mais radiogênicas, com baixos teores de cloreto, as assinaturas do aquíferos são semelhantes à do embasamento, mas podem indicar mistura/ diluição com águas superficiais.

A grande heterogeneidade do contexto geológico da RMR produz as distintas composições químicas e isotópicas nas águas subterrâneas, onde a geologia favorece a salinização local e infiltração de águas novas. As razões ${ }^{87} \mathrm{Sr} /{ }^{86} \mathrm{Sr}$ refletem a contribuição de águas do mar e a interação água-rocha, principalmente a dissolução de minerais. $\mathrm{O}$ aumento da salinização observado nos sistemas aquíferos ao final da estação seca pode ser atribuído à infiltração de águas do mar atuais. No caso do SACB, a oscilação temporal da salinização no aquífero está relacionada ao fluxo ascendente de águas subterrâneas das unidades sotopostas, amplificado pelo alto bombeamento na região (CARY et al. 2015).

\section{4 Águas hidrotermais de Minas Gerais}

O Circuito das Águas de Minas Gerais é uma região turística que abrange 15 municípios, localizada ao sul do estado, enaltecida por sua importância histórica e socieconômica, beleza das paisagens naturais, abundância de parques hidroter- 
mais e de nascentes de águas minerais, que despertam grande interesse na indústria de águas minerais devido a fontes de qualidade e com características físico-químicas particulares. Nesse sentido, foi conduzido uma detalhada investigação das características, origem, gênese e circulação das águas dos parques hidrotermais de Cambuquira, Caxambu, Contendas, Lambari e Marimbeiro, promovido pela Companhia de Desenvolvimento de Minas Gerais (CODEMGE) e Fundação de Desenvolvimento da Pesquisa (FUNDEP). Como produto, foi disponibilizado um Sistema de Informações Geoambientais do Circuito das Águas (SIGA - Circuito das Águas), que apresenta o levantamento e discussão dos dados geológicos, hidrogeoquímicos e isotópicos (estáveis de $\mathrm{O}, \mathrm{H}$ e $\mathrm{C},{ }^{14} \mathrm{C} \mathrm{e}{ }^{87} \mathrm{Sr} /{ }^{86} \mathrm{Sr}$ ) produzidos pelo projeto, assim como recomendações para preservação e utilização das águas minerais (CODEMGE 2018).

Em relação aos isótopos de estrôncio, a comparação entre razões ${ }^{87} \mathrm{Sr} /{ }^{86} \mathrm{Sr}$ de amostras de águas subterrâneas e de rochas contribuíram de maneira significativa na compreensão da origem e circulação das águas subterrâneas do Circuito das Águas. Identificou-se que misturas significativas entre as águas minerais, profundas e ascendentes pelas nascentes, e demais águas dos parques, superficiais e subterrâneas (rasas), são ausentes, exceto nos poucos casos de indícios de contaminação. Há também indícios de que as águas minerais representam aquíferos antigos, com elevada interação água-rocha, cujas surgências as classificam como águas hipotermais (Caxambu) e frias (Cambuquira, Marimbeira, Contendas e Lambari) (CODEMGE 2018).

As águas minerais de Cambuquira apresentam assinaturas isotópicas de estrôncio bem variáveis $(0,7118-0,7330)$, associadas à grande heterogeneidade litológica da região. As assinaturas isotópicas de estrôncio das águas minerais de Caxambu (0,7061-0,7069) assemelham-se às das rochas vulcânicas alcalinas aflorantes no Morro do Caxambu. Nas águas minerais de Contendas, as razões ${ }^{87} \mathrm{Sr} /{ }^{86} \mathrm{Sr}$ são predominantemente radiogênicas $(0,7230-0,7322)$ indicando a interação com rochas quartzosas que afloram na região, enquanto valores menos radiogênicos indicam a interação com rochas do aquífero fraturado xistoso da unidade São Vicente. Nas águas minerais de Lambari, as razões ${ }^{87} \mathrm{Sr} /{ }^{86} \mathrm{Sr}$ são mais radiogênicas $(0,7218-0,7309) \mathrm{e}$ podem ser associadas a dois grupos de rochas da região: os quartzitos da unidade São Tomé das Letras e os xistos da unidade Serra do Turvo. Em
Marimbeiro, as águas minerais apresentam assinaturas com pouca variação $(0,7223-0,7230)$, representativas de rochas intermediárias da unidade São Vicente, próximas a valores do aquífero fraturado xistoso (CODEMGE 2018).

\section{CONSIDERAÇÕES FINAIS - PERSPECTIVAS E OPORTUNIDADES FUTURAS}

Isótopos de estrôncio constituem excelentes traçadores hidrogeoquímicos, devido a algumas características desse elemento, como ser solúvel em meio aquoso, estar presente como elemento-traço na maioria dos minerais e seus isótopos possuírem um caráter conservativo, o que os torna ideais para descrição de interações água-rocha e para compreensão da origem e circulação das águas subterrâneas em contextos hidrogeológicos complexos.

A aplicação deste traçador isotópico em modelos hidrogeológicos contribui para importantes considerações sobre a circulação das águas subterrâneas e sua interação com os distintos compartimentos da Terra, principalmente quando avaliados em conjunto com outros isótopos (comumente de oxigênio e de hidrogênio) e com técnicas hidrogeoquímicas, hidroquímicas e (geo)estatísticas consagradas.

A incipiente utilização dos isótopos de estrôncio em águas subterrâneas no Brasil está associada à pequena oferta de laboratórios, equipe e infraestrutura necessários para a análise, e à complexidade da interpretação dos dados, que requer grande volume de dados complementares, muitas vezes não disponíveis, assim como o conhecimento detalhado do contexto hidrogeológico avaliado, com hipóteses claras acerca das possíveis fontes de estrôncio e mecanismos de mistura. Apesar das dificuldades, os isótopos de estrôncio apresentam grande potencial de crescimento na hidrogeologia, pois se mostram bons traçadores da interação água-rocha e da determinação de fontes em distintos contextos hidrogeológicos brasileiros, como apresentado na revisão dos estudos.

Por se tratar de uma linha de pesquisa isotópica em ascensão, há diversas oportunidades de aplicação dos isótopos de estrôncio na hidrogeologia que podem auxiliar na consolidação desta técnica no Brasil. Algumas dessas oportunidades são: i) produzir dados inéditos, uma vez que a maioria dos sistemas aquíferos não possuem suas assinaturas isotópicas de estrôncio determinadas; ii) incluir as razões ${ }^{87} \mathrm{Sr} r{ }^{86} \mathrm{Sr}$ em trabalhos de monito- 
ramento da qualidade; iii) explorar o papel da interação água-rocha de casos de contaminação; iv) comparar assinaturas isotópicas em restos humanos oriundos de crimes (estudos forenses) ou de estudos arqueológicos, com o arcabouço geológico e hídrico dos locais; v) realizar análises pontuais em rochas para melhorar o entendimento da interação rocha-água e criar valores de referência; vi) associar essa técnica a outras de outros campos do conhecimento.

\section{AGRADECIMENTOS}

Agradecimentos à Fundação de Amparo à Pesquisa do Estado de São Paulo (FAPESP) pela concessão de Auxílio a Pesquisa (Processo

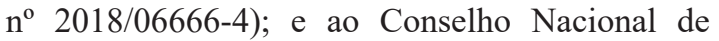
Desenvolvimento Científico e Tecnológico (CNPq) pela concessão da bolsa de mestrado à primeira autora (Processo $n^{\circ}$ 130944/2019-0). Agradecemos especialmente ao editor-chefe Dr. Silvio T. Hiruma e aos revisores anônimos, pelos comentários construtivos que contribuíram na melhoria do trabalho.

\section{REFERÊNCIAS BIBLIOGRÁFICAS}

AGGARWAL, J.; HABITCH-MAUCHE, J.; JUAREZ, C. 2008. Application of heavy stable isotopes in forensic isotope geochemistry: a review. Applied Geochemistry, 23(9): 2658-2666. https://doi. org/10.1016/j.apgeochem.2008.05.016

ALBAREDE, F. 2011. Geoquímica: uma introdução. Oficina de Textos, São Paulo, $400 \mathrm{p}$.

ALLÈGRE, C.J.2008. Isotope Geology. Cambridge University Press, Cambrigde, 534 p. https:// doi.org/10.1017/CBO9780511809323

ANA - AGÊNCIA NACIONAL DE ÁGUAS. 2016. Estudo de vulnerabilidade natural à contaminação e estratégias de proteção do sistema Aquifero Guarani nas áreas de afloramento: relatório final. ANA, Brasília, $113 \mathrm{p}$.

APHA - AMERICAN PUBLIC HEALTH ASSOCIATION. 2005. Standard Methods for the Examination of Water and Wastewater. Washington DC, $21^{\text {st }}$ Edition, 1545 p.
BAKARI, S.S.; AAGAARD, P.; VOGT, R.D.; RUDEN, F.; JOHANSEN, I.; VUAI, S.A. 2013. Strontium isotopes as tracers for quantifying mixing of groundwater in the alluvial plain of a coastal watersched, southeastern Tanzania. Journal of Geochemical Exploration, 130: 1-14. https://doi. org/10.1016/j.gexplo.2013.02.008

BANNER, J.L. 2004. Radiogenic isotopes: systematics and applications to earth surface processes and chemical stratigraphy. Earth Science Reviews, 65(3-4): 141-194. https:// doi.org/10.1016/S0012-8252(03)00086-2

BATAILLE, C.P; CROWLEY, B.E.; WOOLLER, M.J.; BOWEN, G.J. 2020. Advances in global bioavailable strontium isotopes. Paleogeography, Paleoclimatology, Palaeoecology, 555: 1-18. https://doi. org/10.1016/j.palaeo.2020.109849

BAUBLYS, K.A.; HAMILTON, S.K.; HOFMANN, H.; GOLDING, S.D. 2019. A strontium $(87 \mathrm{Sr} / 86 \mathrm{Sr})$ isotopic study on the chemical evolution and migration of groundwaters in a low-rank coal seam gas reservoir (Surat Basin, Australia). Applied Geochemistry, 101: 1-18. https://doi. org/10.1016/j.apgeochem.2018.12.020

BENTLEY, R.A. 2006. Strontium isotopes from the Earth to the archaeological skeleton: a review. Journal of Archaeological Method and Theory, 13(3): 135-187. https://doi. org/10.1007/s10816-006-9009-x

BLUM, J.D.; EREL, Y. 2003. Radiogenic isotopes in weathering and hydrology. In: H.D.Holland \& K.K.Turekian (ed.) Treatise on geochemistry. Elsevier Science, p. 365392. https://doi.org/10.1016/B0-08-0437516/05082-9

BONOTTO, D.M.; ELLIOT, T. 2017. Trace elements, REEs and stable isotopes $(\mathrm{B}, \mathrm{Sr})$ in GAS groundwater, São Paulo State, Brasil. Environmental Earth Science, 76(265): 1-15. https://doi.org/10.1007/s12665-017-6590-0

BORDALO, A.O.; MOURA, C.A.V.; SCHELLER, T. 2007. Determinação da composição isotópica de Estrôncio em águas naturais: exemplos de sua aplicação em águas subsuperficiais da zona costeira na região 
Bragantina-PA. Química Nova, 30(4): 821-827. https://doi.org/10.1590/S010040422007000400012

BRASIL - MINISTÉRIO DO MEIO AMBIENTE. 2007. Águas subterrâneas: um recurso a ser conhecido e protegido. Ministério do Meio Ambiente - MMA, Secretaria de Recursos Hídricos e Meio Ambiente Urbano, Brasília, $40 \mathrm{p}$.

BRENNAN, S.R.; FERNANDEZ, D.P.; ZIMMERMAN, C.E.; CERLING, T.E.; BROWN, R.J.; WOOLLER, M.J. 2014. Strontium isotopes in otoliths of a nonmigratory fish (slimy sculpin): implications for provenance studies. Geochemica et Cosmochima Acta, 149: 32-49. https://doi. org/10.1016/j.gca.2014.10.032

BRENOT, A.; BARAN, N.; PETELET-GIRAUD, E.; NEGREL, P. 2008. Interaction between different water bodies in a small catchment in the Paris basin (Brévilles, France): Tracing of multiple $\mathrm{Sr}$ sources through $\mathrm{Sr}$ isotopes coupled with $\mathrm{Mg} / \mathrm{Sr}$ and $\mathrm{Ca} / \mathrm{Sr}$. Applied Geochemistry, 23(1): 58-75. https:// doi.org/10.1016/j.apgeochem.2007.09.006

BURKE, W.H.; DENISON, R.E.; HETHERINGTON, E.A.; KOEPNICK, R.B.; NELSON, H.F.; OTTO, J.B. 1982. Variation of seawater $87 \mathrm{Sr} / 86 \mathrm{Sr}$ throughout Phanerozoic time. Geology, 10: 516-519. https://doi.org/10.1130/00917613(1982)10<516:VOSSTP $>2.0$. CO;2

CAMPOS, M.S. 2011. Quimioestratigrafia isotópica de carbono e estrôncio e geoquímica de elementos terras raras em formações carbonáticas e ferríferas do cinturão Seridó, nordeste do Brasil. Centro de Tecnologias e Geociências, Universidade Federal de Pernambuco, Recife, Dissertação de Mestrado, 118 p. https://repositorio.ufpe. br/handle/123456789/6464

CAPO, R.C.; STEWARD, B.W.; CHADWICK, O.A. 1998. Strontium isotopes as tracers of ecosystem processes: theory and methods. Geoderma, 82(1-3): 197-225. https://doi. org/10.1016/S0016-7061(97)00102-X

CARY, L.; PETELET-GIRAUD, E.; BERTRAND， G.; KLOPPMAN, W.;
AQUILINA, L.; MARTINS, V.; HIRATA, R.; MONTENEGRO, S.; PAUWELS, H.; CHATTON, E.; FRANZEN, M.; AUROUET, A.; LASSEUR, E.; PICOT, G.; GUERROT, C.; FLEHOC, C.; LABASQUE, T.; SANTOS, J.C.; PAIVA, A.; BRAIBANT, C.; PIERRE, D. 2015. Origins and processes of groundwater salinization in the urban coastal aquifers of Recife (Pernambuco, Brazil): A multi-isotope approach. Science of the Total Environment, 530-531: 411-429. https://doi. org/10.1016/j.scitotenv.2015.05.015

CHADWICK, O.A; DERRY, L.A.; BERN, C.R.; VITOUSEK, P.M. 2009. Changing sources of strontium to soils and ecosystems across the Hawaiian Islands. Chemical Geology, 267(1-2): 64-76. https://doi.org/10.1016/j. chemgeo.2009.01.009

CHENERY, C.; MULDNER, G.; EVANS, J.; ECKARDT, H.; LEWIS, M. 2010. Strontium and stable isotope evidence for diet and mobility in Roman Gloucester, UK. Journal of Archaeological Science, 37(1): 150-163. https://doi.org/10.1016/j.jas.2009.09.025

CLARK, I.D.; FRITZ, P. 1997. Environmental Isotopes in Hydrogeology. Lewis Publishers, Boca Raton, Florida, 342 p.

CODEMGE - COMPANHIA DE DESENVOLVIMENTO DE MINAS GERAIS. 2018. SIGA - Circuito das Águas: Caracterização Geoambiental, Geológica, Geofísica, Hidrogeológica e Hidrogeoquímica do Circuito das Águas de Minas Gerais, com Ênfase nos Parques Hidrominerais de Caxambu, Cambuquira, Marimbeiro, Contendas e Lambari. CODEMGE, Belo Horizonte, 512 p.

COOK, P. 2020. Introduction to isotopes and environmental tracers as indicators of groundwater flow. The Groundwater Project, Guelph, Ontario, 74 p.

COPLEN, T.R.; HERCZEG, A.L.; BARNES, C. 2000. Isotope Engineering - Using Stable Isotopes of the Water Molecule to Solve Practical Problems. In: P.Cook \& A.L.Herczeg (ed.) Environmental Tracers in Subsurface Hydrology. Kluver Academic Publishers, p. 79-110. https://doi. org/10.1007/978-1-4615-4557-6_3 
CRESPI, A.M. 2013. Aplicação de isótopos de estrôncio, oxigênio e hidrogênio como traçadores de anomalias hidrogeoquímicas de bário no Sistema Aquífero Bauru no município Gália (SP). Instituto de Geociências, Universidade de São Paulo, São Paulo, Dissertação de Mestrado, 74 p. https://doi.org/10.11606/D.44.2013.tde06122013-091126

CUNHA, R.B. 2015. Isótopos de $\mathrm{Sr}, \mathrm{C}$ e $\mathrm{O}$ dos carbonatos das formações Sete Lagoas e Lagoa do Jacaré: implicações para a idade deposicional e reconstrução paleoambiental da Bacia Bambuí. Instituto de Geociências, Universidade Federal do Rio Grande do Sul, Porto Alegre, Dissertação de Mestrado, 75 p. http://hdl.handle.net/10183/114401

DA SILVA, D.R.A.; MIZUSAKI, A.M.; ANJOS, S.M.C.; CONCEIÇÃO, R.V. 2006. O método radiométrico $\mathrm{Rb}-\mathrm{Sr}$ aplicado em rochas sedimentares o exemplo da Bacia do Paraná, Brasil. Pesquisas em Geociências, 33(1): 83-100. https://doi.org/10.22456/18079806.19528

DA SILVA, I.R.F. 2015. Caracterização hidrogeoquímica e isotópica $\left({ }^{87} \mathrm{Sr}{ }^{86} \mathrm{Sr}\right)$ dos sistemas aquiferos Barreiras e Pirabas superior nos municípios de Castanhal e Santa Maria do Pará, estado do Pará. Instituto de Geociências, Universidade do Pará, Belém, Dissertação de Mestrado, 59 p. http://repositorio. ufpa.br/jspui/handle/2011/10676

DERRY, L.; BRASIER, M.; CORFIELD, R.; ROZANOV, A.; ZHURAVLEV, A. 1994. $\mathrm{Sr}$ and $\mathrm{C}$ isotopes in Lower Cambrian carbonates from the Siberian craton: a paleoenvironmental record during the "Cambrian explosion". Earth and Planetary Science Letters, 128(3-4): 671-681. https:// doi.org/10.1016/0012-821X(94)90178-3

EDMOND, J. 1992. Himalayan tectonic, weathering processes, and strontium isotope record in marine limestones. Science, 258: 1594-1597. https://doi.org/10.1126/ science.258.5088.1594

FAURE, G. 1986. Principles of Isotope Geology. John Wiley \& Sons, Ohio, 608 p. https://doi. org/10.1017/S0016756800017453
FRISCHKORN, H.; HORN, P.; SANTIAGO, M.M.F.; MENDONÇA, L.A.R. 2002. Origem da água no lençol de Fortaleza. In: ABAS, CONGRESSO BRASILEIRO DE ÁGUAS SUBTERRÂNEAS, 12, Florianópolis, Anais, 17 p.

FROST, C.D.; TONER, R.N. 2004. Strontium isotopic identification of water-rock interaction and ground water mixing. Groundwater, 42(3): 418-432. https://doi. org/10.1111/j.1745-6584.2004.tb02689.x

GALADERT, J.; DUPRE, B.; ALlEGRE, C.J.; NEGREL, P. 1997. Chemical and physical denudation in the Amazon River Basin. Chemical Geology, 142(3-4): 141-173. https:// doi.org/10.1016/S0009-2541(97)00074-0

GLORENNEC, P.; LUCAS, J.P.; MERCAT, A.C.; ROUDOT, A.C.; LE BOT, B. 2016. Environmental and dietary exposure of young children to inorganic trace elements. Environment International, 97: 28-36. https://doi.org/10.1016/j.envint.2016.10.009

GREAVES, J.; ROBOZ, J. 2014. Mass Spectrometry for the Novice. CRC Press, Taylor \& Francis Group, LLC, Boca Raton, FL, 275 p.

HALVERSON, G.P.; DUDÁS, F.O.; MALOOF, A.C.; BOWRING, S.A. 2007. Evolution of the ${ }^{87} \mathrm{Sr} /{ }^{86} \mathrm{Sr}$ composition of Neoproterozoic seawater. Paleogeography, Paleoclimatology, Paleoecology, 256(34): 103-129. https://doi.org/10.1016/j. palaeo.2007.02.028

HIERONYMUS, B.; GODOT, J.M; BOULEGUE, J.; BARIAC, T.; NEGREL, P.; DUPRE, B. 1993. Chimie du fleuve Tocantins et de Rivieres cotieres de l'est du Para (Brésil). In: Jean-Claude Olivry (ed) Grands Bassins Fluviaux Périatlantiques: Congo, Niger, Amazone, Paris, Anais, p. 357-374.

HIRATA, R.C.A.; FERREIRA, L.M.R. 2001. Os aquíferos da bacia hidrográfica do alto Tietê: disponibilidade hídrica e vulnerabilidade à poluição. Revista Brasileira de Geociências, 31(1): 43-50. https://doi.org/10.25249/03757536.20013114350

HOLZ, M.; FRANÇA, A.B.; SOUZA, P.A.; IANNUZZI, R.; ROHN, R. 2010. A 
stratigraph chart of the Late Carboniferous/ Permian succession of the eastern border of the Paraná Basin, Brazil, South America. Journal of South American Earth Sciences, 29(2): 381-399. https://doi.org/10.1016/j. jsames.2009.04.004

INNOCENT, C.; MICHAR, A.; MALENGREAU, N.; LOUBET, M.; NOACK, Y.; BENEDETTI, M.; HAMELIN, B. 1997. Sr isotopic evidence for ion-exachange buffering in tropical laterites from the Paraná, Basin. Chemical Geology, 136(3-4): 219-232. https://doi. org/10.1016/S0009-2541(96)00145-3

JASECHKO, S. 2019. Global isotope hydrogeology - Review. Reviews of Geophysics, 57(3): 835965. https://doi.org/10.1029/2018RG000627

KLOPPMANN, W.; LEROUX, L.; BROMBLET, P.; LE POGAM, Y.; COOPER, A.H.; WORLEY, N.; GUERROT, C.; MONTECH, A.T.; GALLAS, A.M.; AILLAUD, R. 2017. Competing English, Spanish and French alabaster trade in Europe over five centuries as evidenced by isotope fingerprinting. PNAS, 114(45): 11856-11860. https://doi. org/10.1073/pnas.1707450114

LAFFOON, J.E.; DAVIES, G.R.; HOOGLAND, M.L.P.; HOFMAN， C.L. 2012. Spatial variation of biologically available strontium isotopes $\left({ }^{87} \mathrm{Sr} /{ }^{86} \mathrm{Sr}\right)$ in an archipelagic setting: a case study from the Caribbean. Journal of Archaeological Science, 39(7): 2371-2384. https://doi.org/10.1016/j.jas.2012.02.002

LEAL, O. 1994. Vulnerabilidade das águas subterrâneas da Região Metropolitana de Recife. In: R.G. Oliveira (ed) Sistema de Informações para Gestão Territorial da Região Metropolitana do Recife - Projeto SINGRE, Levantamento Gravimétrico da Área Sedimentar da Região Metropolitana do Recife. CPRM/FIDEM, Recife, 29 p.

LUÍS，A.T.; DURÃES，N.; DA SILVA， E.F.; RIBEIRO, S.; SILVA, A.J.F.; PATINHA, C.; ALMEIDA, S.F.P.; AZEVEDO, M.R. 2019. Tracking multiple Sr sources through variations in ${ }^{87} \mathrm{Sr} /{ }^{86} \mathrm{Sr}$ ratios of surface Waters from the Aljustrel massive sulphide mining área: geological versus anthropogenic inputs. Applied Geochemistry, 102: 108-120. https:// doi.org/10.1016/j.apgeochem.2019.01.016
MAILLOUX, J.M.; OGLE, K.; FROST, C.D. 2014. Application of a Bayesian model to infer the contribution of coalbed natural gas produced water to the Powder River, Wyoming and Montana. Hydrological Processes, 28: 23612381. https://doi.org/10.1002/hyp.9784

MALDANER, C.; MARTINS, V.; BERTOLO, R.; HIRATA, R. 2013. Strontium isotopic signature of groundwater from Adamantina aquifer, Bauru Basin, Brasil. Procedia Earth and Planetary Science, 7: 958-961. https:// doi.org/10.1016/j.proeps.2013.03.229

MARTINS, V.; BABINSKI, M.; RUIZ, I.; SATO, K.; SOUZA, S.; HIRATA, R. 2008. Analytical procedures for determining $\mathrm{Pb}$ and $\mathrm{Sr}$ isotopic compositions in water samples by IC-TIMS. Química Nova, 31(7): 1836-1842. https://doi.org/10.1590/S010040422008000700040

MARTINS, V.T.S. 2008. Aplicação de isótopos de $\mathrm{Pb}, \mathrm{Sr}, \mathrm{He}$ O como traçadores da recarga e da contaminação de aquiferos metropolitanos: um exemplo da Bacia do Alto Tietê. Instituto de Geociências, Universidade de São Paulo, São Paulo, Tese de Doutorado, 177 p. https:// doi.org/10.11606/T.44.2008.tde-19122008084523

MCNUTT, R.H. 2000. Strontium Isotopes. In: P.G. Cook \& A.L. Herczerg (ed) Environmental tracers in subsurface hydrology. Springer, Boston, p. 233-257. https://doi. org/10.1007/978-1-4615-4557-6_8

MEGHDADI, A.; JAVAR, N. 2018. Quantification of spatial and seasonal variations in the proportional contribution of nitrate sources using a multi-isotope approach and Bayesian isotope mixing model. Environmental Pollution, 235: 207-222. https://doi. org/10.1016/j.envpol.2017.12.078

METAL MINING JAPAN AGENCY. 2003. Mineral exploration in the Paraná Basin area, the federative republic of Brazil. Japan Internacional Cooperation Agency, $687 \mathrm{p}$.

MILANI, E.J. 1997. Evolução tectonoestratigráfica da Bacia do Paraná e seu relacionamento com a geodinâmica fanerozóica do Gondwana sul-ocidental. Instituto de Geociências, Universidade 
Federal do Rio Grande do Sul, Porto Alegre, Tese de Doutorado, 255 p.

MILANI, E.J. 2004. Comentários sobre a origem e evolução tectônica da Bacia do Paraná. In: V. Mantesso-Neto, A. Bartorelli, C.D. Carneiro \& B.B. Brito-Neves (ed) Geologia do Continente Sul-americano: Evolução da Obra de Fernando Flavio Marques de Almeida. Rio de Janeiro, Beca, p. 265-279.

MILANI, E.J.; RAMOS, V.A. 1998. Orogenias paleozóicas no domínio Sul-Ocidental do Gondwana e os ciclos de subsidência da Bacia do Paraná. Revista Brasileira de Geociências, 28(4): 473-484. http://www.ppegeo.igc.usp. br/index.php/rbg/article/view/11243

MILANI, E.J.; MELO, J.H.G.; SOUZA, P.A.; FERNANDES, L.A.; FRANÇA, A.B. 2007. Bacia do Paraná. Boletim de Geociências da Petrobras, 15(2): 265-287.

MONTAÑEZ, I.; BANNER, J.; OSLEGER, D.; BORG, L.; BOSSERMAN, P. 1996. Integrated $\mathrm{Sr}$ isotope variations and sealevel history of Middle and Upper Cambrian platform carbonates: implications for the evolution of Cambrian seawater ${ }^{87} \mathrm{Sr} /{ }^{86} \mathrm{Sr}$. Geology, 24(10): 917-920. https://doi. org/10.1130/0091-7613(1996)024<0917:ISIV $\mathrm{AS}>2.3 . \mathrm{CO} ; 2$

NIGRO, A.; SAPPA, G.; BARBIERI, M. 2017. Strontium isotopes as tracers of groundwater contamination. Procedia Earth and Planetary Science, 17: 352-355. https://doi. org/10.1016/j.proeps.2016.12.089

OEA - ORGANIZAÇÃO DOS ESTADOS AMERICANOS. 2009. Aquifero Guarani: programa estratégico de ações. OEA, Washington, $424 \mathrm{p}$.

OLIVEIRA FILHO, O.B.Q.; GALARZA, M.A. 2013. Investigação de mistura de águas entre os Sistemas Barreiras e Pirabas com base na assinatura isotópica de Estrôncio ( $\mathrm{Sr}$ ) e hidrogeoquímica em Ananindeua, Belém \& Backgrounds comparativos nos municípios de Benevides e Capanema (PA). Contribuição à Geologia da Amazônia, 8: 177-198.

PARNELL, A.; JACKSON, A. 2013. SIAR: Stable Isotope Analysis in R. Disponível em
https://CRAN.R-project.org/package=siar. Acessado em 14 mar. 2021.

PARNELL, A.C.; PHILLIPS, D.L.; BEARHOP, S.; SEMMENS, B.X.; WWARD, E.J.; MOORE, J.W.; JACKSON, A.L.; GREY, J.; KELLY, D.J.; INGER, R. 2013. Bayesian stable isotope mixing models. Environmetrics, 24 : 387-399. https://doi.org/10.1002/env.2221

PARNELL, A.; INGER, R. 2021. Stable Isotope Mixing Models in $R$ with simmr. Disponível em https://cran.r-project.org/web/packages/ simmr/vignettes/simmr.html. Acessado em 14 abr. 2021.

PETELET-GIRAUD, E.; LUCK, J.M.; OTHMAN, D.B.; JOSEPH, C.; NÉGREL, P. 2016. Chemical and isotopic fingerprinting of small ungauges watershed: how far the hydrological functioning can be understood? Comptes Rendus Geoscience, 348(5): 379386. https://doi.org/10.1016/j.crte.2016.03.001

PETT-RIDGE, J.C.; DERRY, L.A.; KURTS, A.C. 2009. Sr isotopes as a tracer of weathering processes and dust inputs in a tropical granitoid watershed, Luquillo Mountais, Puerto Rico. Geochimica et Cosmochimica Acta, 73(1): 25-43. https://doi.org/10.1016/j. gca.2008.09.032

PHILLIPS, D.L.; INGER, R.; BEARHOP, S.; JACKSON, A.L.; MOORE, J.W.; PARNELL, A.C.; SEMMENS, B.X.; WARD, E.J. 2014. Best practices for use of stable isotope mixing models in food-web studies. NRC Research Press, 92(10): 823-835. https://doi. org/10.1139/cjz-2014-0127

PINO, D.S. 2009. Estudos de isótopos de Estrôncio, Oxigênio e Hidrogênio em um caso de contaminação de Flúor no município de São Paulo. Instituto de Geociências, Universidade de São Paulo, São Paulo, Trabalho de Conclusão de Curso, 71 p.

POSZWA, A.; FERRY, B.; DAMBRINE, E.; POLLIER, B.; WICKMAN, T.; LOUBET, M.; BISHOP, K. 2004. Variation of bioavailable $\mathrm{Sr}$ concentration and ${ }^{87} \mathrm{Sr} /{ }^{86} \mathrm{Sr}$ ratios in boreal forest ecosystems. Biogeochemistry, 67: 1-20. https://doi. org/10.1023/B:BIOG.0000015162.12857.3e 
POTTS, P.J. 1992. A handbook of silicate rock analysis. Springer Science+Business Media New York, $622 \mathrm{p}$.

QUAGGIO, C.S. 2021. Variações nas razões isotópicas ${ }^{87} \mathrm{Sr}{ }^{86} \mathrm{Sr}$ nas águas subterrâneas da porção do Sistema Aquifero Guarani. Instituto de Geociências e Ciências Exatas, Universidade Estadual Paulista "Júlio de Mesquita Filho", Rio Claro, Dissertação de Mestrado, 95 p. http://hdl.handle.net/11449/204533

R CORETEAM. 2021. $R$ : A language and environment for statistical computing. $\mathrm{R}$ Foundation for Statistical Computing. https://www.r-project.org/

REYES, E. 2009. Comportamento dos radioisótopos ${ }^{238} \mathrm{U},{ }^{234} \mathrm{U},{ }^{226} \mathrm{Ra},{ }^{228} \mathrm{Ra}$ e da razão isotópi$\mathrm{ca}^{87} \mathrm{Sr}{ }^{86} \mathrm{Sr}$ em águas subterrâneas extraídas de corpos graníticos fraturados da Suite Intrusiva de Itu (SP). Instituto de Astronomia, Geofísica e Ciências Atmosféricas, Universidade de São Paulo, São Paulo, Tese de Doutorado $238 \mathrm{p}$.

SANTONI, S.; GAREL, E.; GILLON, M.; MARC, V.; MILLER, J.; BABIC, M.; SIMLER, R.; TRAVI, Y.; LEBLANC, M.; HUNEAU, F. 2021. Assessing the hydrogeological resilience of a groundwater-dependent Mediterranea peatland: impact of global change and role of water management strategies. Science of the Total Environment, 768: 1-11. https:// doi.org/10.1016/j.scitotenv.2020.144721

SHAND, P.; DARBYSHIRE, D.P.F.; LOVE, A.J.; EDMUNDS, W.M. 2009. Sr isotopes in natural waters: applications to source characterization and water-rock interaction in contrasting landscapes. Applied Geochemistry, 24(4): 574-586. https://doi. org/10.1016/j.apgeochem.2008.12.011

STEELE, J.D.; PUSHKAR, P. 1973. Strontium isotope geochemistry of the Scioto River basin and the ${ }^{87} \mathrm{Sr} /{ }^{86} \mathrm{Sr}$ ratios of the underlying lithologies. Ohio Journal of Science, 73(6): 331-338. http://hdl.handle.net/1811/22183

STUEBER, A.M.; PUSHKAR, P.; BALDWIN, A.D. 1972. Survey of ${ }^{87} \mathrm{Sr} /{ }^{86} \mathrm{Sr}$ ratios and total strontium concentrations in Ohio stream and ground waters. The Ohio Journal of Science, 72(2): 97-104. http://hdl.handle.net/1811/5681

STUEBER, A.M.; BALDWIN, A.D.; CURTIS JR., J.B.; PUSHKAR, P.; STEELE, J.D. 1975. Geochemistry of strontium in the Scioto River Drainage Basin, Ohio. Geological Society of America Bulletin, 86(7): 892-896. https://doi.org/10.1130/00167606(1975)86<892:GOSITS >2.0.CO;2

TAMAYO, J.C.S. 2004. Quimioestratigrafia de isótopos de C e Sr de mármores do complexo São Caetano, zona transversal, província estrutural da Borborema: implicações regionais e globais. Centro de Tecnologia e Geociências, Universidade Federal de Pernambuco, Recife, Dissertação de Mestrado, 53 p. https://repositorio.ufpe.br/handle/123456789/6569

VAUTOUR, G.; POIRIER, A.; WIDORY, D. 2015. Tracking mobility using human hair: what can we learn from lead and strontium isotopes? Science and Justice, 55(1): 63-71. https://doi.org/10.1016/j.scijus.2014.10.001

VEIZER, J. 1989. Strontium isotopes in seawater through time. Annual Reviews of Earth Planetary Sciences, 17: 141-167. https://doi. org/10.1146/annurev.ea.17.050189.001041

VEIZER, J.; ALA, D.; AZMY, K.; BRUCKSCHEN, P.; BUHL, D.; BRUHN, F.; CARDEN, G., DIENER, A., EBNETH, S.; GODDERIS, Y.; JASPER, T.; KORTE, C.; PAWELLEK, F.; PODLAHA, O.; STRAUSS, H. $1999 .{ }^{87} \mathrm{Sr} /{ }^{86} \mathrm{Sr}, \delta^{13} \mathrm{C}$ and $\delta^{18} \mathrm{O}$ evolution of Phanerozoic seawater. Chemical Geology, 161(1-3): 59-88. https://doi.org/10.1016/ S0009-2541(99)00081-9

WEBB-ROBERTSON, B.; KREUZER, H.; HART, G.; EHLERINGER, J.; WEST, J.; GILL, G.; DUCKWORTH, D. 2012. Bayesian integration of isotope ratio for geographic sourcing of castor beans. Journal of Biomedicine and Biotechnology, 450967: 1-8. https://doi.org/10.1155/2012/450967

WEST, J.B.; HURLEY, J.M.; DUDAS, F.O.; EHLERINGER, J.R. 2009. The stable isotope ratio of Marijuana: II. Strontium isotopes relate to geographic origin. Journal of 
Forensic Sciences, 54(6): 1261-1269. https:// doi.org/10.1111/j.1556-4029.2009.01171.x

WILHELMSON, H.; AHLSTROM, T. 2015. Iron age migration on the island of Öland: apportionment of strontium by means of Bayesian mixing analysis. Journal of Archaelogical Science, 64: 30-45. https://doi. org/10.1016/j.jas.2015.09.007
XIE, X.; WANG, Y.; ELLIS, A.; SU, C.; LI, J.; LI, M.; DUAN, M. 2013. Delineation of groundwater flow paths using hydrochemical and strontium isotope composition: a case study in high arsenic aquifer systems of the Datong basin, northern China. Journal of Hydrology, 476(7): 87-96. https://doi. org/10.1016/j.jhydrol.2012.10.016

\section{Endereço dos autores:}

Carolina Stager Quaggio e Didier Gastmans - Centro de Estudos Ambientais, Universidade Estadual Paulista, Av. 24A, 1515, Bela Vista, CEP: 13.506-900, Rio Claro, SP, Brasil. E-mails: stager.quaggio@, unesp.br; didier.gastmans@unesp.br

Veridiana Teixeira de Souza Martins - Departamento de Geologia Sedimentar e Ambiental, Instituto de Geociências, Universidade de São Paulo, Rua do Lago, 562, Cidade Universitária, CEP 05508-080, São Paulo, SP, Brasil. E-mail: veridian@usp.br

Artigo submetido em 14 de abril de 2021, aceito em 11 de junho de 2021. 